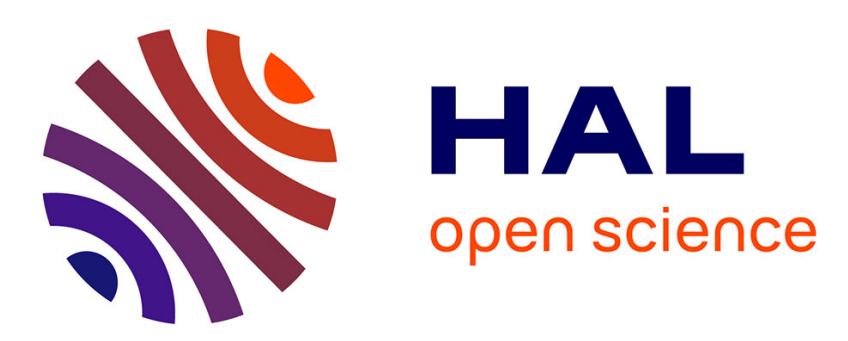

\title{
On the feasibility and interest of applying territorial Life Cycle Assessment to determine subnational normalisation factors
}

\author{
L. Roibás, Eléonore Loiseau, A. Hospido
}

\section{- To cite this version:}

L. Roibás, Eléonore Loiseau, A. Hospido. On the feasibility and interest of applying territorial Life Cycle Assessment to determine subnational normalisation factors. Science of the Total Environment, 2018, 626, pp.1086-1099. 10.1016/j.scitotenv.2018.01.126 . hal-02607490

\section{HAL Id: hal-02607490 \\ https://hal.inrae.fr/hal-02607490}

Submitted on 16 May 2020

HAL is a multi-disciplinary open access archive for the deposit and dissemination of scientific research documents, whether they are published or not. The documents may come from teaching and research institutions in France or abroad, or from public or private research centers.
L'archive ouverte pluridisciplinaire HAL, est destinée au dépôt et à la diffusion de documents scientifiques de niveau recherche, publiés ou non, émanant des établissements d'enseignement et de recherche français ou étrangers, des laboratoires publics ou privés. 


\section{On the feasibility and interest of applying territorial Life Cycle Assessment to determine subnational normalisation factors}

Laura Roibás $^{1, *}$, Eléonore Loiseau ${ }^{2}$, Almudena Hospido $^{1}$

*Corresponding author. E-mail address: laura.roibas.cela@usc.es

1. Group of Environmental Biotechnology, Department of Chemical Engineering, Institute of Technology, Universidade de Santiago de Compostela, 15782 Santiago de Compostela, Galicia, Spain.

2. ITAP, Irstea, Montpellier SupAgro, ELSA Research Group, Univ Montpellier, Montpellier, France.

\section{Keywords}

Life cycle assessment, normalization factors, territorial LCA, midpoint, hybrid LCA, subnational references

\section{Abbreviations:}

LCIA, Life Cycle Impact Assessment; UNEP-SETAC, United Nations Environment Programme Society of Environmental Toxicology and Chemistry; NACE, Nomenclature statistique des Activités économiques dans la Communauté Européenne; GDP, Gross Domestic Product; CFC, Chlorofluorocarbons; HCFC, Hydrochlorofluorocarbons; NMVOC, Non-Methane Volatile Organic Compounds.

\section{Abstract}

Normalisation is an optional step in Life Cycle Assessment (LCA), often used in decision making since it helps interpreting the results of LCA studies with regard to some reference information. The applicable ISO standard recommends considering different reference systems to guarantee the robustness of the normalisation step, and so the availability of different normalisation datasets becomes of high relevance.

Life Cycle Impact Assessment (LCIA) methods provide normalisation factors (NFs) for global and regional areas, but no NFs are proposed for smaller areas such as local or subnational scales. The aim of this paper is to evaluate the feasibility of using territorial LCA approach to determine subnational NFs. Normalisation datasets for both Galician (NW Spain) production and consumption activities have been calculated considering a life cycle perspective. In addition to this, the normalisation datasets calculated for Galicia have been used to evaluate two food products produced and/or consumed in the region as case studies. Then, the normalised results have been compared to those obtained using different reference systems (Europe and the World), calculated following the same methodology (ReCiPe).

A qualitative uncertainty analysis of the NFs has been carried out, and the usefulness of territorial LCA to determine them has been discussed. It was concluded that territorial LCA is a promising way to determine NFs but that some improvements could be made, which have also been pointed out here.

\section{Introduction}

Life Cycle Assessment (LCA) is a tool designed to evaluate the environmental performance of a product $^{1}$ throughout its entire life cycle (ISO, 14040:2006). It consists of four mandatory stages, i.e. i) goal and scope definition, ii) inventory analysis, iii) impact assessment, and iv)

\footnotetext{
${ }^{1}$ Following the terminology of LCA International Standards, the term "product" includes services (ISO, 14040:2006).
} 
interpretation; and of several optional ones including normalisation, grouping, weighting, or data quality analysis.

This paper focuses on the normalisation step, in which the impact assessment results are compared to a certain reference. This step serves several purposes, i.e. it helps interpreting the impact assessment results and finding inconsistencies among them, it can facilitate the communication of the results to non-practitioners, it can serve as a first step before other optional phases such as weighting, and it can also ease decision making when trade-offs exist (Bare et al., 2006). Trade-offs refer here to the issues arising in comparative studies, when identifying the alternative with the best environmental performance is not straightforward, due to the different scores obtained in the various impact categories.

The normalisation of the life cycle impacts of a certain product or process is carried out following Eq. (1).

$$
N_{i}=\frac{C_{i}}{N F_{i}}
$$

For a certain impact category $i, N_{i}$ is represents its normalised result, $C_{i}$ is the impact of the product or process under study and $\mathrm{NF}_{\mathrm{i}}$ is the normalisation factor, i.e. the impact of the reference against which the results are compared. The choice of the reference system largely influences the results and the way to interpret them. There are two main types of normalisation, i.e. internal and external (Pizzol et al., 2016).

The internal normalisation is used to compare the environmental performance of different alternative scenarios, and so the impact results of the different alternatives are compared to a certain reference from the same study (Norris, 2001). This can be done in several ways, such as division by baseline (the impacts of each alternative are divided by those of a certain one, chosen as baseline scenario) or division by maximum (the impacts of each category are divided by the maximum value found for that category throughout all the alternatives). By definition, internal normalisation can only be used in comparative scenarios (Pizzol et al., 2016), and it can lead to incongruent results if a subsequent weighting step is carried out (Norris, 2001), and so the current recommendation of the United Nations Environment Programme and the Society of Environmental Toxicology and Chemistry (UNEP-SETAC) is to use external normalisation instead (Verones et al., 2017).

In the external normalisation, the reference system is usually a geographical area (which may be global, regional, national, or local (ISO, 14044:2006)) at a specific period of time (usually one year) (Lautier et al., 2010). There are two main types of external normalisation, i.e. the production based approach and the consumption based one. The production based approach derives NFs from the direct environmental flows occurring within a certain area, linked to the human activities. The consumption based one includes both the direct and indirect life cycle environmental flows (i.e. occurring within a certain area or elsewhere) linked to the final consumption of that area (Breedveld et al., 1999). It should be noted that the terms consumption and production are not necessarily linked to the type of human activities (e.g. the production based approach usually includes direct emissions from households, not linked to any productive activity), but to the boundaries considered. At the global scale, both approaches yield the same NFs and reflect the total worldwide environmental impacts.

The reference system chosen to calculate NFs must be consistent with the system boundaries of the assessed product (Lautier et al., 2010). Considering that nowadays most raw materials required travel around the world, the reference system should account for all life cycle emissions. For instance, using the ReCiPe European NFs to normalise LCIA results of the annual consumption of two Galician brands of coffee seems inappropriate, as both system boundaries are completely different. On the one hand, most of the coffee supply chain and the related environmental flows take place outside Europe, while on the other hand the ReCiPe European NFs follow the aforementioned production based approach, and thus they only include the direct environmental flows taking place in the European continent. Another way to keep the same system boundaries is to use global scale NFs. 
Neither the global scale nor the life cycle based approach, however, has achieved widespread development due to the difficulty of data gathering and to the extrapolation requirements of global inventories, since usually the worldwide environmental interventions need to be inferred from a few countries for which data are available. To the best of our knowledge, only a few sets of both types of normalisation factors exist, using different LCIA methodologies and reference years and areas: three for the consumption based approach, for The Netherlands in 1993/1994 using CML (Breedveld et al., 1999), for Finland in 2005 (Dahlbo et al., 2013) following ReCiPe, and for Canada in 2005 using three different LCIA methodologies (Lautier, 2010); and three for the worldwide reference: in 1990 and 1995 using CML (Huijbregts et al., 2003), in 1994 following EDIP97 (Stranddorf et al., 2005), and in 2000 using ReCiPe (Sleeswijk et al., 2008).

More numerous are the production based regional (i.e., continental and national) normalisation datasets, again calculated with different methodologies for different reference years, available for Europe (Sala et al., 2015), the United States (Kim et al., 2013), and individual countries (Slapnik, 2015). Only the most recent regional normalisation datasets have been cited here, while a detailed list of those existing before 2013 can be found in (Laurent and Hauschild, 2015).

In any case, no subnational normalisation references exist so far, even though considering regional particularities can lead to significant deviations when compared to large scale ones (Slapnik, 2015). Subnational NFs can be useful for designing local policies and identifying hotspots in a given area.

Considering these recommendations and needs, this paper explores the possibilities and interests of determining subnational life cycle based normalisation factors. These factors will be computed according to the territorial LCA approach (Loiseau et al., 2013).Territorial LCA is a hybrid methodology, combining bottom-up (process LCA) with top-down (input-output LCA) approaches to evaluate the overall environmental impacts of all the production and consumption activities that take place within a region (Loiseau et al., 2013). Both NFs for Galician production and consumption activities will be determined according to a life cycle perspective, also called consumption-based approach in the literature. As already mentioned, in most existing normalisation studies, production NFs refer to those only including direct environmental flows, while consumption NFs include both direct and indirect ones. This terminology can be misleading as it is not directly linked to the type of activities included in the reference system boundaries unlike the NFs computed in this study. Our approach is more consistent with that used in the LCA of individual products. Moreover, the normalisation factors will be computed according to existing LCA databases, thus limiting discrepancies with conventional LCAs.

The objective of this study is to evaluate the suitability of using territorial LCA to calculate normalisation factors, using Galicia (NW Spain) as case study due to the following reasons: i) there are numerous Galician LCA case studies applied to specific products or activities in all sectors, but none for all regional production and consumption activities; ii) the territorial LCA methodology developed to collect environmental flows for all production and consumption activities has never been used to obtain normalization factors; iii) Galicia has particular economic characteristics, where the primary sector plays a more important role than in the rest of Spain, so determining specific regional NFs could be interesting for local decisionmaking to assess the contribution of a product or an activity to the overall regional impacts in a more robust way, iv) the Spanish Autonomous Communities are regions with transferred competencies in environmental issues from the National Government, and local decisionmakers need quantitative tools to design their policies.

The NFs obtained are then applied to two sets of existing LCAs of products produced and consumed in the region. The methodological issues found when calculating normalisation factors are discussed, and the normalised results of the case studies are compared using different normalisation references. Last, the feasibility and interest of using the territorial LCA 
methodology to calculate NFs is evaluated, and the main advantages and disadvantages of the approach are presented, along with recommendations for future studies aimed at the same purpose. The normalisation factors obtained can be used in subsequent studies in Galicia, and they can also largely contribute to the body of knowledge of the topic and set a pathway for the determination of other normalisation references.

\section{Methods}

Territorial LCA is a methodology developed by (Loiseau et al., 2013), aimed at providing LCA based information to support decision making in land planning. This hybrid methodology combines top-down and bottom-up approaches to determine the environmental impacts of all production and consumption activities that take place within a certain territory, following a life cycle perspective and thus including all the upstream impacts no matter where they occur.

The consumption activities are split into five subactivities (Kaenzig and Jolliet, 2006), i.e., food ${ }^{2}$, goods, services, housing and transport; while the production ones are divided into eight main groups following the $\mathrm{NACE}^{3}$ classification of economic activities (Eurostat, 2008), i.e., primary sector, quarrying, energy, building, manufacturing activities, transport, services and end of life. The impacts of some of the aforementioned activities are calculated following a top-down approach (i.e. food, goods and services in consumption and manufacturing in production), while the remaining ones are calculated using a bottom-up methodology. In both cases, the impact calculation consists of combining activity descriptors with Life Cycle Inventories (LCls), which relate the descriptors to a certain amount of environmental flows (i.e. resource consumptions and substance emissions). In the top-down approach, the activity descriptors are economic values, which are then combined with the $\mathrm{LCl}$ data contained in the United States Environmental Input Output (USEIO) database (Suh, 2010). The representativeness of this database is not optimal; however, this is the only $I O$ database that computes more than a thousand substances, thus allowing quantifying numerous environmental impact categories. In the bottom-up approach, the descriptors are physical quantities, which are combined with numerous individual LCls, taken from the Ecoinvent v 3.1 database (Wernet et al., 2016) or from local studies when available. For all territorial activities, all upstream stages are considered for computing LCls except for the service sector: due to the lack of data, only the impacts linked to the consumption of electricity, heat and tap water, and to wastewater treatment have been accounted for.

When applying this methodological approach, the annual impacts of the chosen environmental impact categories are obtained both for consumption and production activities. Moreover, both consumption and production impacts are split into the aforementioned activities. These annual impacts are then used as the normalisation factors.

To calculate NFs, territorial LCA is applied to Galicia (Roibás et al., 2017), a region located in the North West (NW) of Spain (Figure 1). The region has a population of 2,732,347 inhabitants (IGE, 2015c), of which only 998,000 are employed (IGE, 2015b), a Gross Domestic Product (GDP) of 53,865 M€ (INE, 2016b) (5\% of the Spanish GDP) and annual household expenditure figures of 27,907 M€ (INE, 2014b) (5\% lower than the Spanish average), all of them corresponding to 2014. Regarding the time framework of the study, the activity descriptors used correspond to different years. The most recent values (2014) were always used when available, but in practice they reflect a range of years (2009-2014). It was decided not to extrapolate the older results to 2014, since this would increase the uncertainty of the normalisation factors (Slapnik, 2015).

\footnotetext{
2 The food consumption activity includes food, beverages and tobacco consumption.

${ }^{3}$ Statistical classification of economic activities in the European Community. The acronym derives from the French: Nomenclature statistique des Activités économiques dans la Communauté Européenne
} 


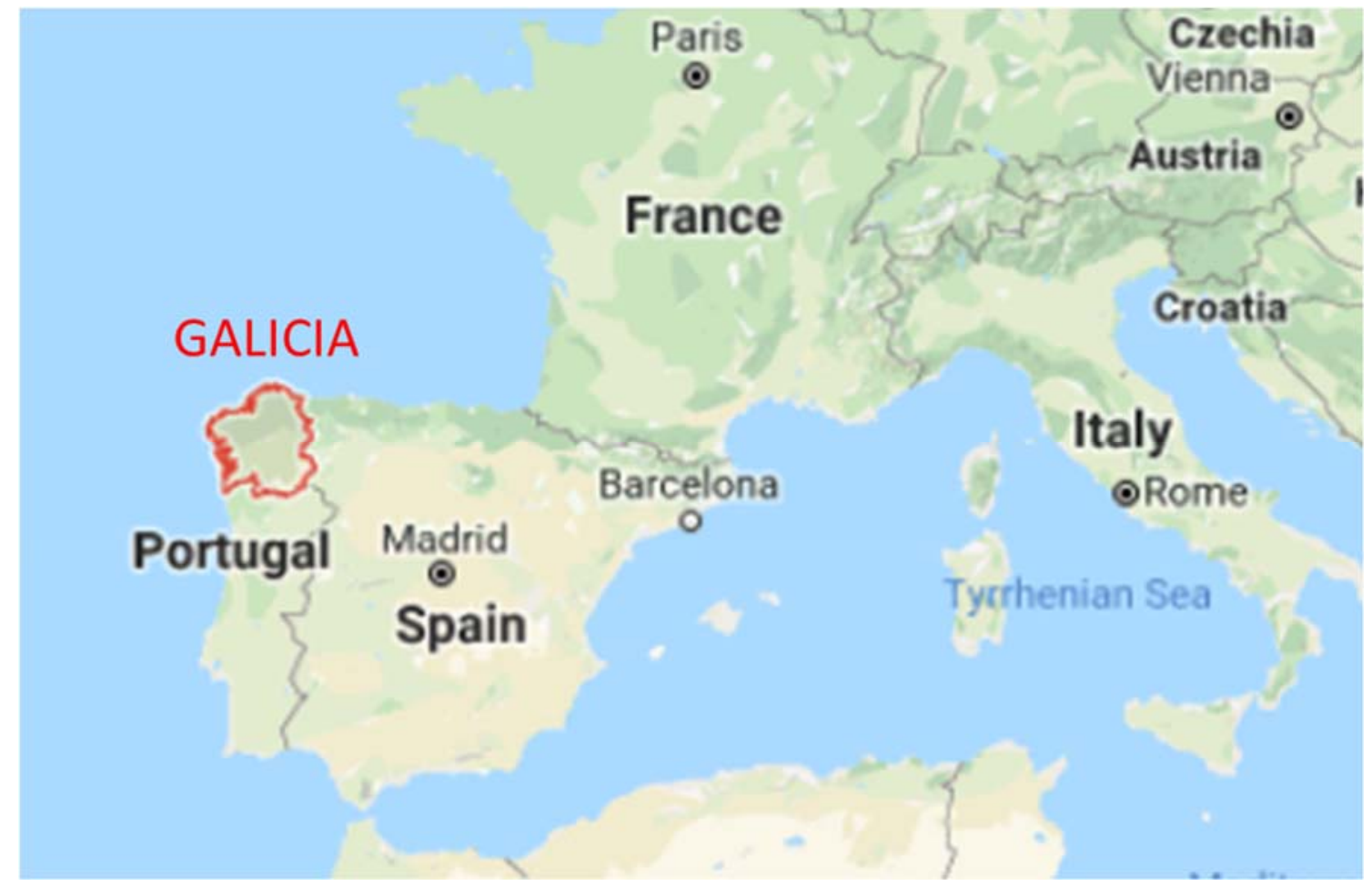

Figure 1: Geographical location of the Galician region (in red).

It should be also noted that, due to the methodology used, both the impacts of production and consumption can be affected by double counting. The LCl of all activities is computed by adding LCls of individual products belonging to one activity, and some of them can belong to the same supply chain (business to business or business to consumer) and hence be quantified several times. Within production, double counting has been avoided following (Roibás et al., 2017): when goods from a Galician sector are purchased and used as raw materials by other sector, their impacts are assigned to the latter. Within consumption, the $\mathrm{LCl}$ data used in bottom-up activities is modified to make sure that the impacts included in the top-down ones are excluded there. A detailed list of all the descriptors and LCl data used to determine both production and consumption impacts in Galicia can be found in section S1 of the supplementary material.

Fifteen normalisation values have been obtained using ReCiPe 2008 Hierarchist v1.13 (Goedkoop et al., 2009), corresponding to the following impacts: Climate change (CC), Ozone depletion (OD), Terrestrial acidification (TA), Freshwater eutrophication (FE), Marine eutrophication (ME), Human toxicity (HT), Photochemical oxidant formation (POF), Particulate matter formation (PMF), Terrestrial ecotoxicity (TET), Freshwater ecotoxicity (FET), Marine ecotoxicity (MET), Agricultural land occupation (ALO), Water depletion (WD), Metal depletion (MD) and Fossil depletion (FD). Three environmental impact categories were removed due to the lack of data for certain environmental flows in the USEIO database (ionising radiation, urban land occupation and natural land transformation). The authors are aware that a new version of the ReCiPe methodology has been recently released (Huijbregts et al., 2017), but no normalisation factors are available so far. Since one of the objectives of the paper is to compare the applicability of our NFs to that of the existing ones and to provide an alternative normalisation dataset, the previous version of ReCiPe has been used.

The NFs determined here for Galician production and consumption will therefore be tested in the evaluation of two comparative case studies, i.e. a locally produced foodstuff and an imported product consumed in Galicia.

In the first case study, two cradle-to-gate productive scenarios of canned tuna processed in Galicia are compared. More specifically, the former supply chain of tuna fishing and processing 
is compared to the current one (Hospido et al., 2006; Roibás et al., 2015b) taking into account that both strategies locate their last productive stages in Galicia.

In the second case study, organic and conventional Ecuadorian banana consumed in Galician households will be compared. The $\mathrm{LCl}$ data of this cradle-to-grave comparative study are taken from previous papers published by the authors (Roibás et al., 2015a, 2016).

\section{Results}

This section presents the normalisation factors obtained for Galician production and consumption, and then the results from the characterisation stage and the normalised results of the two case studies are compared.

\subsection{Normalisation factors}

\subsubsection{Normalisation factors of Galician production activities}

Table 1 displays the NFs obtained for Galician total production, and the main contributing substances to each impact category. As expected, only a few substances dominate most impact categories (Huijbregts et al., 2003; Sleeswijk et al., 2008).

NFs are also presented per capita, per unit of GDP and per number of employed people. To the best of our knowledge, the latter has never been used in previous studies where normalisation factors are provided, but the authors believe that it can be a useful metric in normalisation from the production perspective, when different reference systems are compared. So, expressing the production NFs per number of employed people can offer a different perspective in contexts of economic recession or in regions with a very aged population, and both situations occurred in Galicia within the reference years of the study.

It should be noted that the NFs are also made available split into the production activities considered, so as to increase their usability. Only the production activity contributing the most to each impact category will be mentioned in the analysis of the results shown below, while a full list of the disaggregated NFs can be found in section S2 of the supplementary material.

A detailed discussion of the normalisation values and their major contributors can be found in section 4.1 . 
Author-produced version of the article published in Science of the Total Environment $2018, N^{\circ} 626, p .1086-1099$

The original publication is available at http://linkinghub.elsevier.com/retrieve/pii/S0048969718301499

Doi: 10.1016/j.scitotenv.2018.01.126

Table 1: Normalisation factors of Galician production for fifteen impact categories, expressed in absolute terms, per capita and per worker. For each impact category, the five main contributing substances or resources are ranked based on their percentage contribution to the total impact.

\begin{tabular}{|c|c|c|c|c|c|c|c|c|c|}
\hline \multirow{2}{*}{$\begin{array}{l}\text { Impact } \\
\text { category (unit) }\end{array}$} & \multicolumn{4}{|c|}{ Normalisation factors } & \multicolumn{5}{|c|}{ Main contributors } \\
\hline & $\begin{array}{c}\text { Total } \\
\text { annual }\end{array}$ & Per capita & $\begin{array}{c}\text { Per } \\
\text { employed }\end{array}$ & Per $€$ GDP & $1^{\text {st }}$ & $2^{\text {nd }}$ & $3^{\text {rd }}$ & $4^{\text {th }}$ & $5^{\text {th }}$ \\
\hline $\begin{array}{l}\mathrm{CC}^{4} \\
\left(\mathrm{~kg} \mathrm{CO}_{2} \text { eq }\right)\end{array}$ & $3.41 \mathrm{E}+10$ & $1.25 \mathrm{E}+04$ & $3.41 E+04$ & $6.32 \mathrm{E}-01$ & Carbon dioxide (77\%) & Methane (12\%) & $\begin{array}{l}\text { Dinitrogen monoxide } \\
(7 \%)\end{array}$ & $\begin{array}{l}\text { Methane biogenic } \\
(3 \%)\end{array}$ & \\
\hline $\begin{array}{l}\text { OD } \\
\text { (kg CFC-11 eq) }\end{array}$ & $1.80 \mathrm{E}+04$ & $6.60 \mathrm{E}-03$ & $1.81 \mathrm{E}-02$ & $3.35 \mathrm{E}-07$ & HCFC-140 (25\%) & HCFC-22 (12\%) & CFC-10 (12\%) & Halon 1001 (11\%) & CFC-114 (9\%) \\
\hline $\mathrm{TA}(\mathrm{kg} \mathrm{SO} \mathrm{eq}$ ) & $2.39 \mathrm{E}+08$ & $8.76 \mathrm{E}+01$ & $2.40 \mathrm{E}+02$ & $4.44 \mathrm{E}-03$ & Ammonia (54\%) & Sulphur oxides (29\%) & Nitrogen oxides (17\%) & & \\
\hline $\begin{array}{l}\mathrm{ME} \\
(\mathrm{kg} \mathrm{N} \mathrm{eq)}\end{array}$ & $4.75 \mathrm{E}+07$ & $1.74 \mathrm{E}+01$ & $4.76 \mathrm{E}+01$ & $8.81 \mathrm{E}-04$ & $\begin{array}{l}\text { Nitrate to water } \\
(59 \%)\end{array}$ & $\begin{array}{l}\text { Nitrogen to water } \\
(18 \%)\end{array}$ & Ammonia to air (10\%) & $\begin{array}{l}\text { Ammonium ion to } \\
\text { water }(6 \%)\end{array}$ & $\begin{array}{l}\text { Nitrogen oxides to } \\
\text { air }(6 \%)\end{array}$ \\
\hline $\begin{array}{l}\text { HT } \\
\text { (kg 1,4-DB eq) }\end{array}$ & $4.66 \mathrm{E}+09$ & $1.70 E+03$ & $4.67 E+03$ & $8.64 \mathrm{E}-02$ & $\begin{array}{l}\text { Manganese to water } \\
(44 \%)\end{array}$ & $\begin{array}{l}\text { Arsenic to water } \\
(8 \%)\end{array}$ & Mercury to air (7\%) & Acrolein to air (5\%) & Arsenic to air (4\%) \\
\hline $\begin{array}{l}\text { POF } \\
\text { (kg NMVOC) }\end{array}$ & $9.31 \mathrm{E}+07$ & $3.41 \mathrm{E}+01$ & $9.33 E+01$ & $1.73 \mathrm{E}-03$ & Nitrogen oxides (77\%) & Sulphur oxides (6\%) & Carbon monoxide (6\%) & $\begin{array}{l}\text { NMVOC, unspecified } \\
(4 \%)\end{array}$ & $\begin{array}{l}\text { Methane, total } \\
(2 \%)\end{array}$ \\
\hline $\begin{array}{l}\text { PMF } \\
\text { (kg PM10 eq) }\end{array}$ & $1.08 \mathrm{E}+08$ & $3.95 E+01$ & $1.08 \mathrm{E}+02$ & $2.00 \mathrm{E}-03$ & $\begin{array}{l}\text { Particulates, all sizes } \\
(57 \%)\end{array}$ & Ammonia (16\%) & Nitrogen oxides (15\%) & Sulphur oxides (13\%) & \\
\hline $\begin{array}{l}\text { TET } \\
\text { (kg 1,4-DB eq) }\end{array}$ & $6.86 \mathrm{E}+07$ & $2.51 \mathrm{E}+01$ & $6.87 E+01$ & $1.27 \mathrm{E}-03$ & $\begin{array}{l}\text { Metam-sodium } \\
\text { dihydrate to soil } \\
(56 \%)\end{array}$ & $\begin{array}{l}\text { Cypermethrin to soil } \\
(14 \%)\end{array}$ & Metolachlor to soil (8\%) & Atrazine to soil (6\%) & $\begin{array}{l}\text { 2-(thiocyanomethy } \\
\text { Ithio) } \\
\text { benzothiazole (2\%) }\end{array}$ \\
\hline $\begin{array}{l}\text { FET } \\
\text { (kg 1,4-DB eq) }\end{array}$ & $4.04 \mathrm{E}+08$ & $1.48 \mathrm{E}+02$ & $4.05 \mathrm{E}+02$ & $7.51 \mathrm{E}-03$ & $\begin{array}{l}\text { Copper to water } \\
(59 \%)\end{array}$ & $\begin{array}{l}\text { Beryllium to water } \\
(16 \%)\end{array}$ & Nickel to water $(10 \%)$ & $\begin{array}{l}\text { Manganese to water } \\
(3 \%)\end{array}$ & Zinc to water (2\%) \\
\hline $\begin{array}{l}\text { MET } \\
\text { (kg 1,4-DB eq) }\end{array}$ & $3.55 \mathrm{E}+08$ & $1.30 \mathrm{E}+02$ & $3.56 \mathrm{E}+02$ & $6.59 \mathrm{E}-03$ & $\begin{array}{l}\text { Copper to water } \\
(58 \%)\end{array}$ & $\begin{array}{l}\text { Beryllium to water } \\
(18 \%)\end{array}$ & Nickel to water (11\%) & $\begin{array}{l}\text { Manganese to water } \\
(3 \%)\end{array}$ & Zinc to water (2\%) \\
\hline $\mathrm{MD}$ (kg Fe eq) & $1.16 \mathrm{E}+09$ & $4.24 \mathrm{E}+02$ & $1.16 \mathrm{E}+03$ & $2.15 \mathrm{E}-02$ & Iron (60\%) & Copper (11\%) & Nickel (10\%) & Chromium (8\%) & Manganese (6\%) \\
\hline FD (kg oil eq) & $1.73 \mathrm{E}+10$ & $6.35 \mathrm{E}+03$ & $1.74 \mathrm{E}+04$ & $3.22 \mathrm{E}-01$ & Natural gas (32\%) & Crude oil (29\%) & Energy, unspecified (23\%) & Coal $(16 \%)$ & \\
\hline $\operatorname{ALO}\left(m^{2} a\right)$ & $1.18 \mathrm{E}+10$ & $4.31 \mathrm{E}+03$ & $1.18 \mathrm{E}+04$ & $2.19 \mathrm{E}-01$ & - & & & & \\
\hline WD $\left(\mathrm{m}^{3}\right)$ & $3.54 \mathrm{E}+09$ & $1.30 \mathrm{E}+03$ & $3.55 \mathrm{E}+03$ & $6.57 \mathrm{E}-02$ & - & & & & \\
\hline
\end{tabular}

${ }^{4}$ CC results have already been published in (Roibás et al., 2017), but using the IPCC most updated set of characterisation factors (IPCC, 2013). 
Climate change is dominated by carbon dioxide emissions, being electricity production its main contributing sector. Regarding ozone depletion, hydrochlorofluorocarbons (HCFCs) are responsible for $44 \%$ of the impacts, followed by chlorofluorocarbons (CFCs, 35\%) and halons (16\%). Motor vehicle manufacturing, an important industrial activity in Galicia, is the major contributor to this category.

Only three substances have characterisation factors for terrestrial acidification in ReCiPe, being ammonia the major contributor (Table 1). The main contributing activity of this category corresponds to the manufacture of food products.

Phosphorous emissions are responsible for freshwater eutrophication, while nitrogen ones cause marine eutrophication. Both impacts are split among the different compounds and compartments to which each substance is emitted: direct emissions to water (which include nutrient leaching from agricultural soil) are the main cause of the impacts in both categories. While, as expected, agricultural and livestock production is the major contributor to $\mathrm{ME}$, the main contributor to FE here is electricity production (from coal burning).

A set of heavy metals dominates the human toxicity impact, being manganese emissions to water the main contributor, while nitrogen oxides dominate photochemical oxidant formation. Electricity production is the main contributing activity to both impact categories.

The manufacture of food products is the main contributor to particulate matter formation, while the agricultural and livestock sector causes the largest impacts in terrestrial ecotoxicity. The main contributing substances to TET are pesticides emitted to soil.

Waste management is responsible for most of the emissions of freshwater and marine ecotoxicity categories, and copper emissions to water represent the highest share of both impacts.

Regarding resource depletion, iron, copper and nickel are the main contributors to metal depletion, being vehicle manufacturing the main contributing activity. When considering fossil depletion, the environmental impacts correspond mainly to natural gas and crude oil, followed by a generic category (unspecified energy) which also includes (among others) those two. Petroleum refining is the production activity that contributes the most to FD. The main contributing activities to both resource depletion impact categories seem quite intuitive and thus they do not show any modelling inconsistencies.

Agricultural land occupation and water consumption are the only contributors to ALO and WD categories, and thus their results are not further split (Table 1). Forestry is the main contributor to agricultural land occupation, and food production to water depletion.

\subsubsection{Normalisation factors of Galician consumption activities}

Table 2 displays the NFs obtained for Galician consumption, both for total consumption and consumption expressed per capita and per Euro of household expenditure.

The NFs of Galician consumption are lower than those of its production, reflecting the fact that only $37 \%$ of Galician products are consumed by local households, while $86 \%$ of the products purchased by Galician residents come from the region. Both figures reflect monetary shares and not physical volumes, and the second one could be misleading. This $86 \%$ figure includes the expenditures on the services sector (food and drinking places, health services, real estate...). The activities of the services sector are always located in Galicia, and expenditures in services represent a major share of the budget of the Galician inhabitants. However, that a service (e.g. a restaurant) is located in Galicia does not mean that it only serves Galician products. Thus, even though it is said that $86 \%$ of the expenditures of the Galician inhabitants correspond to Galician products, this should not be interpreted as a high level of resource selfsufficiency in the region as a lot of resources are imported.

Again, the NFs split into the five consumption activities considered is available in section S2 of the supplementary material, so as to allow comparing the impacts of a certain product consumed in Galicia to those belonging to the same activity. 
Author-produced version of the article published in Science of the Total Environment, 2018, N 626, p. $1086-1099$

The original publication is available at http://linkinghub.elsevier.com/retrieve/pii/S0048969718301499

Doi: 10.1016/j.scitotenv.2018.01.126

Table 2: Normalisation factors of Galician consumption for fifteen impact categories, expressed in absolute terms, per capita and per euro of consumer expenditure. For each impact category, the five main contributing substances or resources are ranked based on their percentage contribution to the total impact.

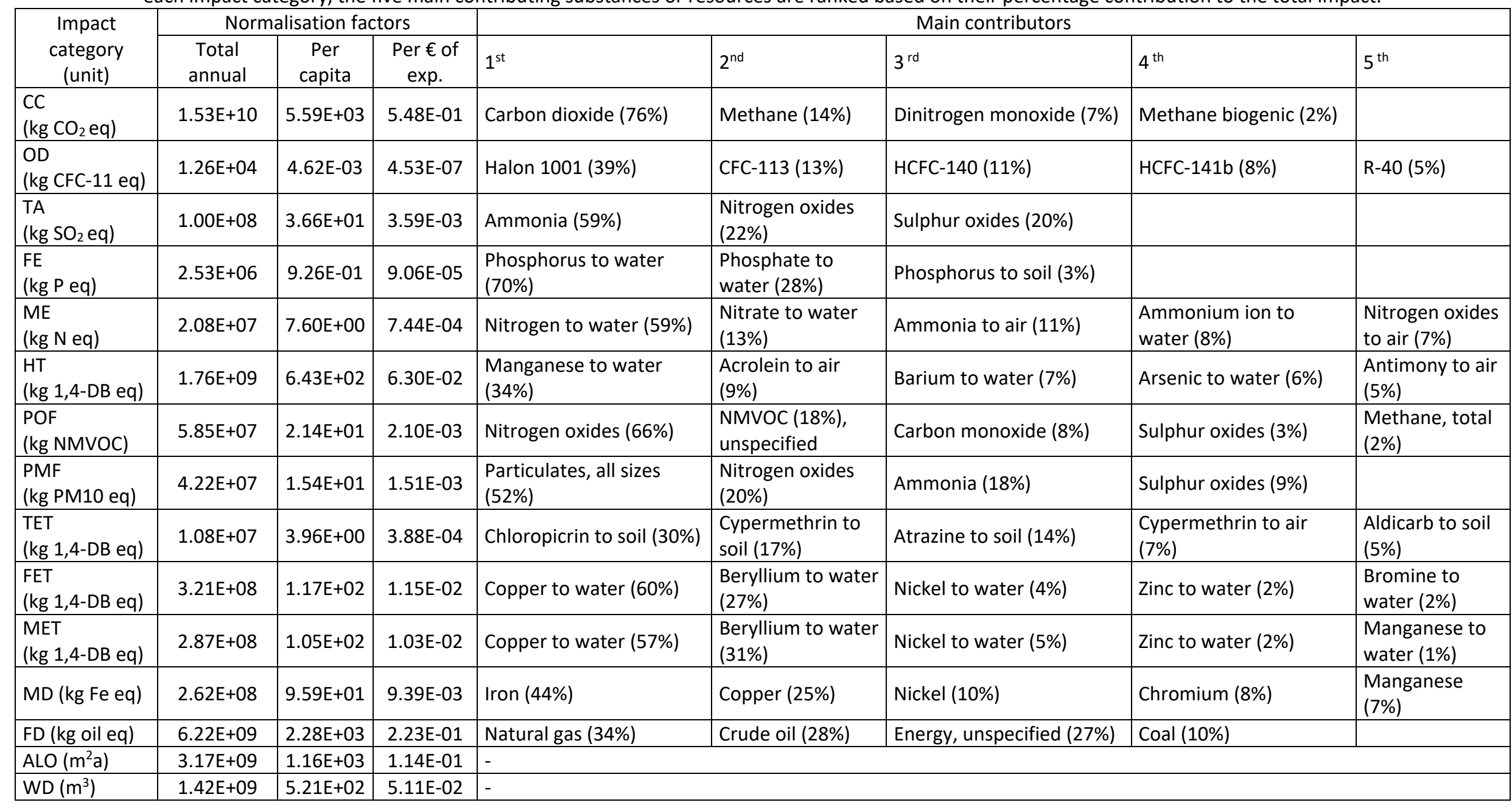


Climate change is again dominated by carbon dioxide emissions, and its main contributing activity is housing, and more specifically the energetic consumption of houses and flats.

Regarding ozone depletion, halons are responsible for $44 \%$ of the impacts, followed by CFCs (26\%) and HCFCs (24\%). Food consumption (fruits and vegetables) is the major contributor to this category.

Ammonia is the main contributing substance to terrestrial acidification (Table 2), while the main contributing activity is food consumption, and more specifically the consumption of animal products.

As found for consumption, phosphorous and nitrogen emissions to water are the major contributors to freshwater and marine eutrophication, respectively. The consumption of food products (again dominated by animal based consumption) is the main contributor to both impacts.

Manganese emissions to water dominate the human toxicity impact, being housing (and more specifically energy consumption) responsible here for the largest share of the emissions.

Regarding photochemical oxidant formation, nitrogen oxides bear the largest share of the impacts, while the second contributor is unspecified Non-Methane Volatile Organic Compounds (NMVOC) emissions. This contributor groups a series of compounds which are not further split into their different substances in the inventory data, for which more specific characterisation factors exist. The first individual NMVOC that appears as a major source of impact is toluene (0.5\%). Regarding the consumption activities, both housing (energetic inputs) and food consumption (animal products) are responsible for the largest share of the emissions. Particulate matter formation is mainly caused by food consumption (and especially consumption of animal based products).

The main contributors to terrestrial ecotoxicity are the emissions of pesticides to agricultural soils, mainly chloropicrin, cypermethrin and atrazine. Food consumption is once again responsible for the largest share of the emissions, which in this case correspond to tobacco products and to the pesticides used in tobacco cultivation.

Emissions of copper, beryllium and zinc to water dominate both freshwater and marine ecotoxicity categories, being responsible for more than $90 \%$ of the impacts in both categories, while pesticides play a marginal role (less than $3 \%$ in total). Housing is the main contributing activity to both FET and MET impacts, in both cases due to household waste management (and more specifically to the share of waste which is incinerated).

Regarding resource depletion, iron, copper and nickel are the main contributors to metal depletion, being housing (energetic impacts) the most impacting activity. When fossil depletion is considered, the main contributing substances are natural gas and crude oil, being goods consumption (of fuels for personal transport) the most impacting activity.

The largest share of agricultural land occupation corresponds to the housing activity, due to the use of wood in building construction, while food consumption (animal products) largely dominates water depletion.

As already mentioned, Galician consumption impacts are lower than those of production for all impact categories. The main differences are found in TET (6.4 increase factor), MD (4.4) and ALO (3.7). These impacts correspond to those sectors in which the Galician production is outstanding, i.e. the primary sector (agricultural and wood production), and the motor vehicle sector. The results indicate that each year, much more products of both sectors are produced in Galicia than consumed by its inhabitants. This can be easily seen in the case of motor vehicles: the vehicle factory located in Galicia manufactured 450,000 cars in 2014 (ABC, 2015), while Galician inhabitants only purchased 35,000 units (Faro de Vigo, 2015). Within the primary sector, potato production causes the major TET impacts: Galicia produces yearly more than $473 \mathrm{kT}$ (MAGRAMA, 2014) while each inhabitant only consumes $30 \mathrm{~kg}$ (MAPAMA, 2015), that results in a total consumption of $83 \mathrm{kT}$. Differences in the forestry and timber sector are more difficult to quantify due to the great variability of wood products commercialised, but the differences are expected to respond to the same pattern. 


\subsection{Using Galician NFs for LCAs of products}

The results of the impacts of the two aforementioned case studies are presented here, used as an example of application of both production NFs (in the case of canned tuna) and consumption NFs (banana).

\section{Canned tuna production case study}

The first case study compares the environmental performance of canned tuna obtained with two productive scenarios: the previous one (2005) and the current one (2014). In the previous scenario, tuna was captured in the Pacific, Indian and Atlantic oceans, and then transported by several cargo vessels to the processing facilities in Galicia, where tuna was cut and canned. In the current scenario, tuna is fished in the Pacific and Atlantic oceans only, and a pre-processing stage has been added in El Salvador to handle Pacific tuna. In this stage, fish is cut and cooked, and thus only frozen tuna loins are transported to Galicia in refrigerated container ships. These loins enter the Galician processing factory at a later stage than tuna coming from the Atlantic Ocean, which undergoes all processing stages in the region. This cradle-to-gate case study ends at the factory gate, when tuna cans leave the facilities.

Figure 2 displays the comparative results of the impact characterisation step for both productive scenarios, expressed per Euro of product (in 2017 Euros). The detailed numeric results can be found in section S3 of the supplementary material.

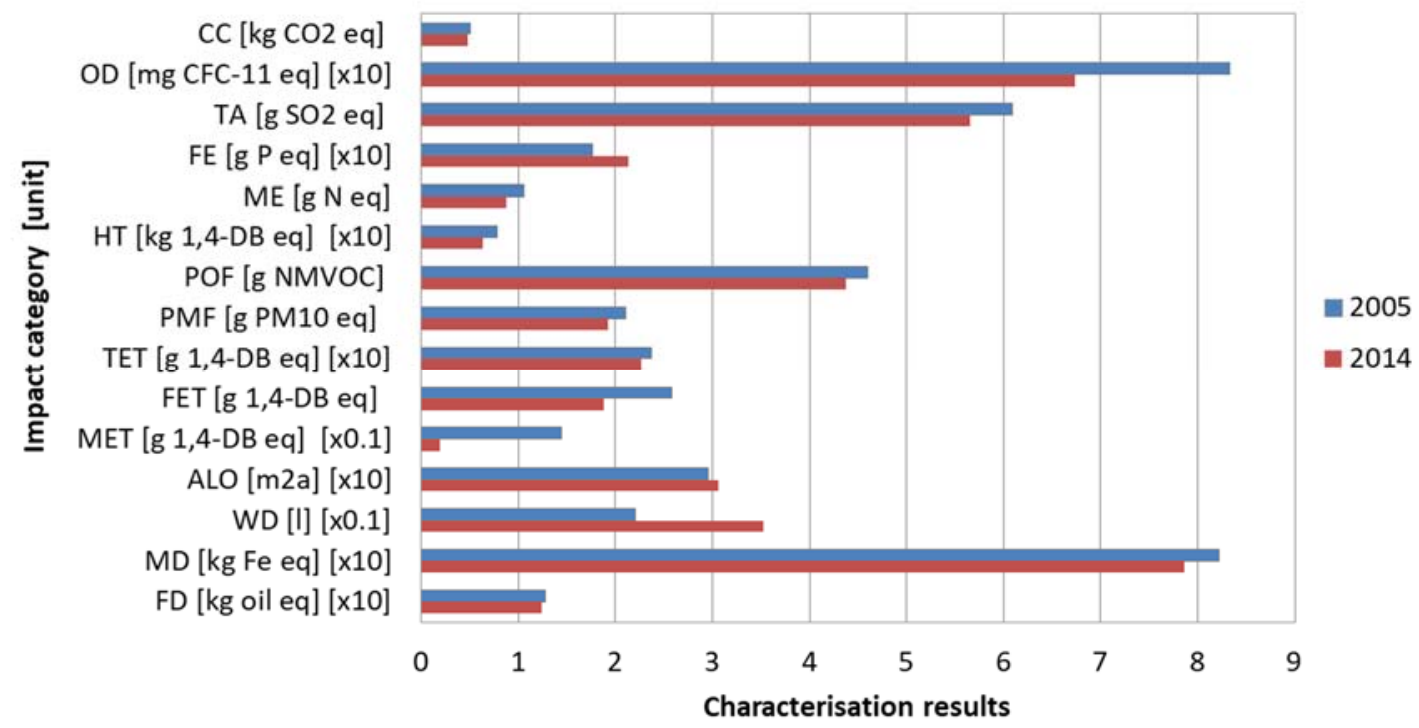

Figure 2: Comparative impact assessment results of 1 Euro of canned tuna considering two productive scenarios: the 2005 supply chain and the current (2014) one. Fifteen impact categories have been considered: CC(climate change), OD (ozone depletion), TA (terrestrial acidification), FE (freshwater eutrophication), ME (marine eutrophication), HT (human toxicity), POF (photochemical oxidant formation), PMF (particulate matter formation), TET (terrestrial ecotoxicity), FET (freshwater ecotoxicity), MET (marine ecotoxicity), ALO (agricultural land occupation), WD (water depletion), MD (metal depletion) and FD (fossil depletion).

The characterisation results (Figure 2, S3) have been normalised using the Galician production NFs. To do so, NFs expressed per Euro of 2014 GDP (Table 1) have been converted into 2017 figures, by taking into account the rises in consumer prices (INE, 2016a). The normalised results obtained (Figure 3 ) add a new decision element by identifying the most important contributions to the Galician impacts (Pizzol et al., 2016). 


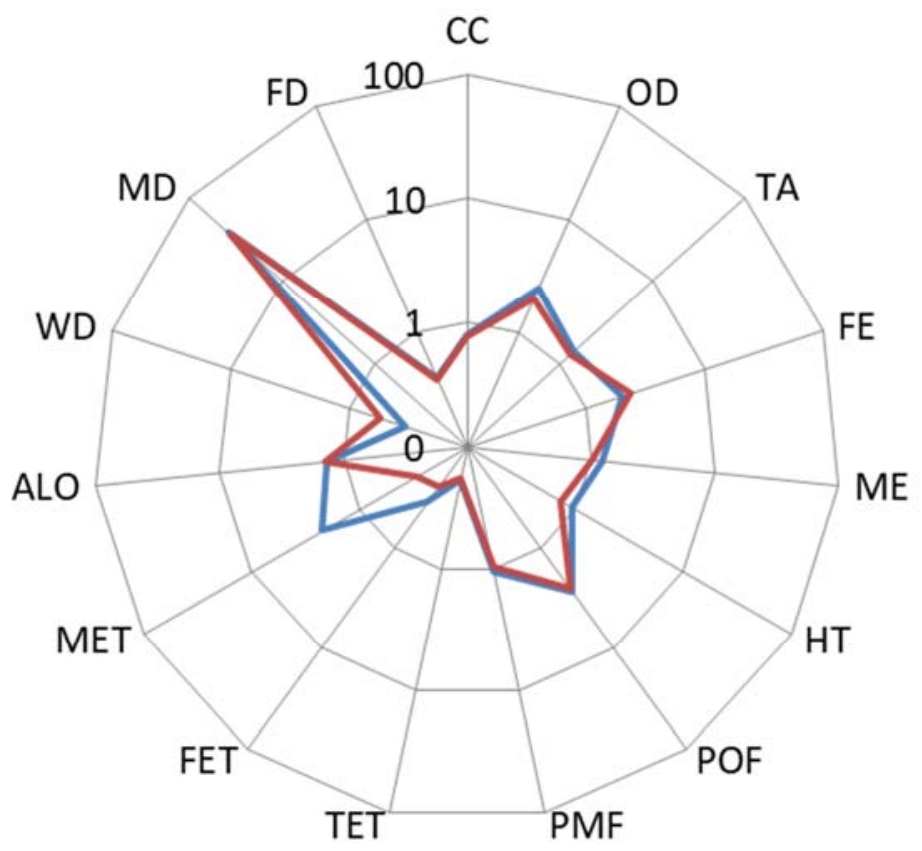

—Old supply chain (2005)

—Current supply chain (2014)

Figure 3: Normalised results of the canned tuna production case study. Please note that values in the axis are in logarithmic scale. Fifteen impact categories have been considered: CC(climate change), OD

(ozone depletion), TA (terrestrial acidification), FE (freshwater eutrophication), ME (marine eutrophication), HT (human toxicity), POF (photochemical oxidant formation), PMF (particulate matter formation), TET (terrestrial ecotoxicity), FET (freshwater ecotoxicity), MET (marine ecotoxicity), ALO (agricultural land occupation), WD (water depletion), MD (metal depletion) and FD (fossil depletion).

When comparing the normalised results, the relevance of the metal depletion caused by canned tuna (mainly due to can production) is highlighted, and so the minor difference between both alternatives in this category (the new situation reduces the impacts by $4 \%$ due to the higher tinplate recycling rate) acquires relevance. Nevertheless, and given the major influence of canned tuna production in Galician MD, alternative packaging materials should be looked for.

The normalisation step also reveals the importance of the reductions achieved in the marine ecotoxicity impacts. These reductions represent an important environmental improvement since canned tuna production contributes largely to that impact category in Galicia. Broadly speaking, the normalised results point at an overall better environmental performance of the new situation, and also help identifying new improvement requirements (mainly the need to continue lowering metal consumption). FD, ALO and WD are the only environmental categories in which the new supply chain causes higher impacts. The main reason is the higher quantity of olive oil used in the current production process than in the former one.

The LCIA results of the case study (Figure 2 ) showed that the impact categories in which the environmental performance of both supply chains differed the most were WD (by 60\%) and MET (by $87 \%$ ). Thus, if only the LCIA results were considered for decision making, these would be the impact categories to focus on. The normalised results (Figure 3), however, show that MD is the impact category which needs the most attention, although the 2014 scenario only shows a $4 \%$ decrease. This proves that the normalisation step provides additional information that can be valuable for local stakeholders to highlight where improvements should be done to decrease the overall impacts of the area in a significant way. 


\section{Banana consumption case study}

The second case study evaluates the impacts of the annual consumption of bananas of a Galician inhabitant, comparing the environmental performance of two alternatives: conventional and organic bananas. Both types of fruit are grown in Ecuador, and transported in refrigerated vessels to the port of Rotterdam, where they are ripened and then taken by trucks to the distribution centres in Galicia. The impacts linked to transport to the Galician households and to consumption (e.g. peel waste management) have also been included in this cradle-to-grave case study.

Figure 4 displays the comparative results of the impact characterisation step for both products, per annual amount of banana consumed per inhabitant (9.8 kg (INE, 2014a)). The detailed numeric results can be found in section $\mathrm{S} 3$ of the supplementary material.

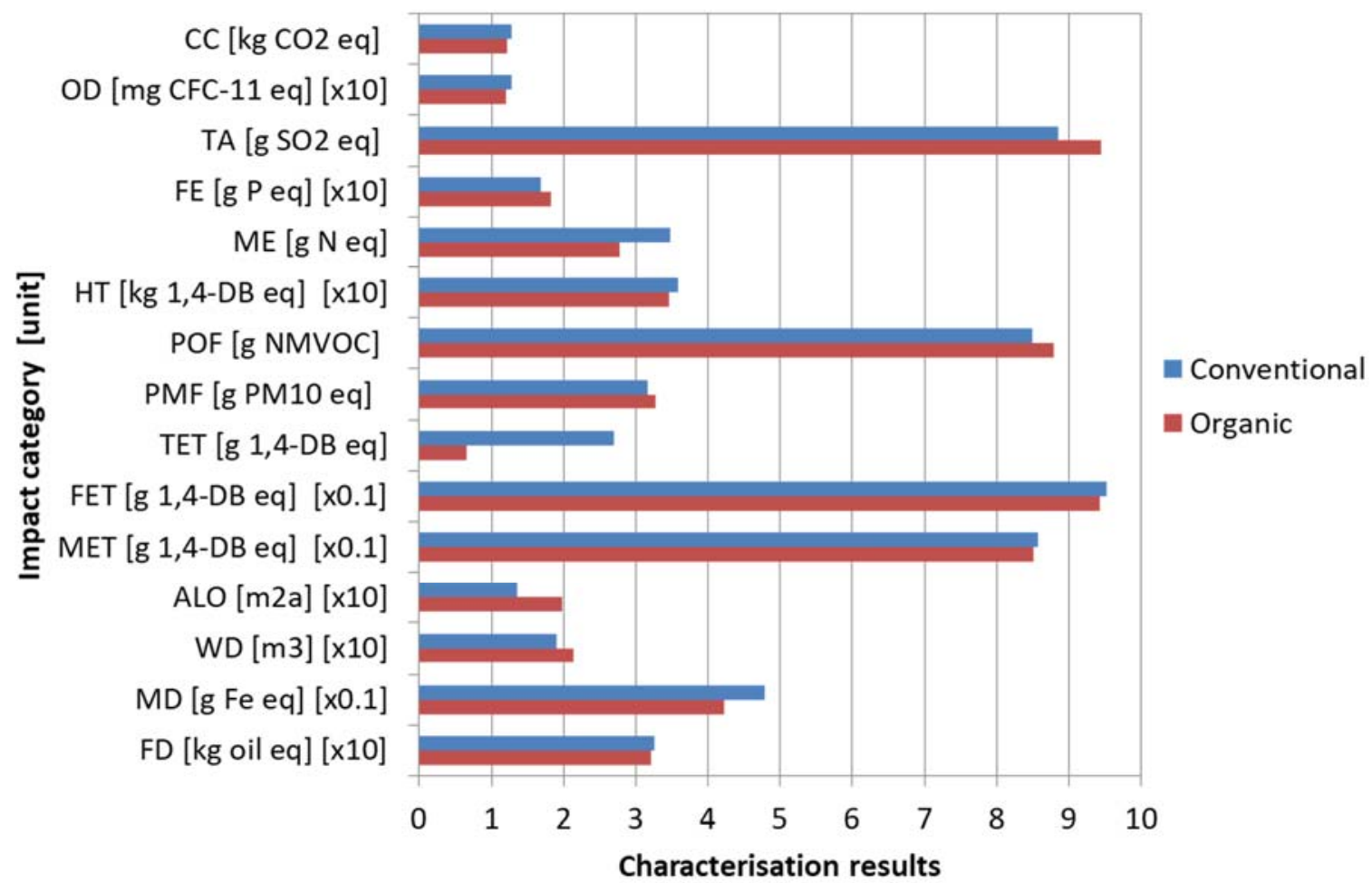

Figure 4: Comparative impact assessment results of the yearly consumption of banana $(9.8 \mathrm{~kg})$ by a Galician inhabitant, comparing conventional and organic options. Fifteen impact categories have been considered: CC(climate change), OD (ozone depletion), TA (terrestrial acidification), FE (freshwater eutrophication), ME (marine eutrophication), HT (human toxicity), POF (photochemical oxidant formation), PMF (particulate matter formation), TET (terrestrial ecotoxicity), FET (freshwater ecotoxicity), MET (marine ecotoxicity), ALO (agricultural land occupation), WD (water depletion), MD (metal depletion) and FD (fossil depletion).

The results shown in figure 4 have been normalised using the NFs calculated here for Galician consumption per capita (Figure 5). This choice is consistent with the functional unit of our case study: the annual banana consumption per capita. The normalisation step is aimed at facilitating the interpretation of the aforementioned results, and at solving the existing tradeoffs by identifying the most important contributions to the Galician impacts. 


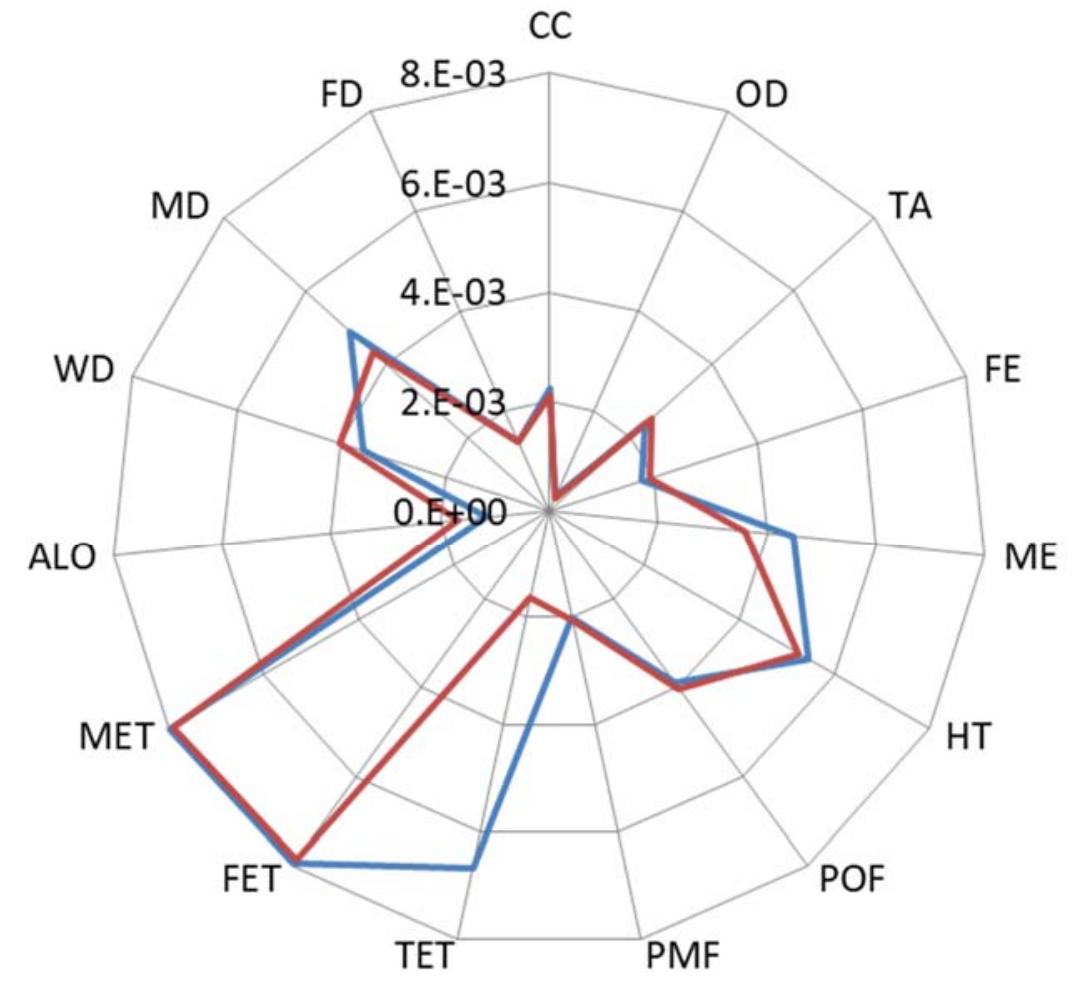

Conventional banana

\section{_Organic banana}

Figure 5: Normalised results of both conventional and organic banana consumption in Galicia. Fifteen impact categories have been considered: CC(climate change), OD (ozone depletion), TA (terrestrial acidification), FE (freshwater eutrophication), ME (marine eutrophication), HT (human toxicity), POF (photochemical oxidant formation), PMF (particulate matter formation), TET (terrestrial ecotoxicity), FET (freshwater ecotoxicity), MET (marine ecotoxicity), ALO (agricultural land occupation), WD (water depletion), MD (metal depletion) and FD (fossil depletion).

The normalised results reveal that banana consumption contributes largely to ecotoxicity categories. Impacts of organic banana are lower in the three of them, but differences are only significant in terrestrial ecotoxicity, where choosing organic bananas reduces impacts by almost $80 \%$ (Figure 4). The results can help highlighting the advantages of choosing organic bananas, and also help identifying those categories in which further action is required to lower the impacts of both products: marine and freshwater ecotoxicity. Based on the normalised results, choosing organic bananas seems the most responsible option in the light of the results shown in figure 5 .

The LCIA results of banana consumption (Figure 4) showed that the impact categories in which the environmental performance of both supply chains differed the most were TET (by $76 \%$ ) and ALO (by $46 \%$ ). Thus, if only the LCIA results were considered for decision making, these would be the impact categories to focus on. The normalised results (Figure 5), however, show that FET and MET are the impact categories which need the most attention to attempt to decrease the overall impacts of the Galician region, even though the differences between both alternatives are not that significant ( $1 \%$ for both of them). The normalisation step also provides valuable information to local decision makers here. 


\section{Discussion}

On a first subsection, both normalisation datasets displayed in section 3.1 are discussed: the main contributing substances to each category are further evaluated and methodological issues found are detailed. On a second subsection, the normalised results of the case studies shown in section 3.2 are compared to those obtained with different normalisation references. Last, the suitability of using territorial LCA to obtain normalisation datasets is evaluated.

\subsection{Main contributors: contextualization an methodological issues}

As often found in the literature (Breedveld et al., 1999; Sala et al., 2015; Sleeswijk et al., 2008), climate change impacts are dominated by $\mathrm{CO}_{2}$ emissions, both for consumption and production datasets. No discrepancies were found between the modelling approaches used in both $\mathrm{LCl}$ sources (Ecoinvent and USEIO database), and the substance coverage is similar in both datasets.

Within the ozone depletion impacts, the contribution of Halon 1001 stands out. Its prevalence is only found in those consumption and production activities modelled using the USEIO database, being negligible in the remaining ones. Halon 1001 (also named methyl bromide) is a pesticide banned from the EU (ECHA, 2017), and whose production has also been restricted in the US since 2005 (EPA, 2017). Thus, its presence as a major contributor in the Galician NFs responds to the use of an outdated (2002) North American dataset, which in this case does not properly reflect the current situation. This results in a low reliability of the OD NF, especially in the consumption dataset: if the impacts of Halon 1001 were left out of the study, this NF would only be $60 \%$ of that shown in table 1 . However, doing this would probably result in an underestimation of the NFs, since other pesticides also causing environmental impacts are surely used instead. Thus, the uncertainty of this NF should be taken into account when the Galician NFs are used. An uncertainty score is assigned to all NFs in section 4.3.1.Regarding terrestrial acidification, only three substances have characterisation factors in ReCiPe, and ammonia emissions are responsible for the largest share of the impacts both for Galician consumption and production. All three contributing substances are included in both $\mathrm{LCl}$ sources, and thus no incongruences have been found. Moreover, the prevalence of ammonia emissions in the European acidification impacts has also been found by other authors (Sala et al., 2015; Sleeswijk et al., 2008).

Regarding eutrophication, emissions to water are responsible for the largest share of both freshwater and marine impacts, as found by (Sleeswijk et al., 2008) for Europe. As expected, the production and consumption of agricultural and livestock products is responsible for the largest share of both eutrophication impacts, with one exception: the main contributor to the FE of the Galician production is electricity generation. This counterintuitive result (especially considering the high relevance of the primary sector in the region) responds to the inclusion in the inventories of long term emissions: in the particular case of electricity production, $\mathrm{FE}$ impacts correspond to coal mining (and more specifically to the landfilling of the spoils generated). When long term emissions are considered, all the P compounds contained in this spoils are considered to be (eventually) released in the environment, and thus represent a major contribution to FE. Long term emissions should always be included in LCA assessments so as to accurately assess end of life impacts (Doka, 2009; Hellweg and Frischknecht, 2004), and so our NFs have included long term emissions to guarantee consistency with future LCA studies also including those impacts. It should be noted, however, that the USEIO database does not consider the same system boundaries, thus excluding long term emissions. The authors acknowledge that the use of different sources of inventory data having different system boundaries represents an inconsistency at the LCl level, and that it can clearly affect the accuracy of the results, and so an alternative set of normalisation factors, excluding long term emissions, is made available in section S4 of the supplementary material, both for Galician production and consumption. 
Even though HT impacts are also significantly affected by the inclusion/exclusion of long term emissions (their exclusion would lower the impacts by $54 \%$ in consumption and $60 \%$ in production), the main contributing substances are consistent between $\mathrm{LCl}$ data sources. Acrolein emissions represent an important share of both production and consumption impacts. This biocide (also named 2-propenal), was not even considered to calculate ReCiPe normalisation factors (Sleeswijk et al., 2008), while a more recent European normalisation dataset (Sala et al., 2015), in which the ILCD methodology was used, also found acrolein to be a non-negligible contributor (4\%) to the human toxicity category. Both our results and those of Sala et al. point at a noteworthy lack of completeness of the ReCiPe HT NF. This lack of completeness leads to an underestimation of the factor, and to inaccuracies when the ReCiPe normalisation dataset is applied.

Regarding POF impacts, it should be noted that the USEIO database always distinguishes among specific NMVOCs, thus not using the generic substance (NMVOC, unspecified) often included in Ecoinvent and found to be a major contributor here. This lack of differentiation is a common issue in NF determination (Dahlbo et al., 2013; Sleeswijk et al., 2008), and it can largely affect the accuracy of the POF impact (Laurent and Hauschild, 2015).

Regarding particulate matter formation, the direct emission of particles is the major contributor to PMF of both Galician consumption and production, as also found by (Sala et al., 2015) for Europe. These particles have not been split here among sizes since they all share the same characterisation factor, and no incongruences have been found among $\mathrm{LCl}$ sources in PMF.

TET impacts of consumption and production are dominated by a series of pesticides. Some of them (chloropicrin, atrazine) have been banned from the European Union(ECHA, 2017) but not from the US, and so the inventory data used is expected to overestimate their contribution to TET impacts. Contrarily, metam-sodium dehydrate, is a pesticide absent in the USEIO database but included in Ecoinvent inventories, which appears as a major contributor in TET of Galician consumption. This is another inconsistency found between the two major $\mathrm{LCl}$ sources of the study, and it can affect the accuracy of the toxicity normalisation factors.

When focusing on FET and MET impacts, a clear dominancy of a few substances is found (Cu, $\mathrm{Be}, \mathrm{Li})$, which is not frequently seen in the literature, where toxicity impacts are split among numerous contributors (Laurent and Hauschild, 2015; Sleeswijk et al., 2008). It should be noted, however, that numerous authors point at the large uncertainties of the NFs of toxicity impacts (Lautier et al., 2010; Sleeswijk et al., 2008), both due to the uncertainties of the fate models but also to the emission inventory data used. In this case, the dominance of these substances is linked to the Ecoinvent-based modelling, and it responds again to the inclusion of long-term emissions considered in the database. This explains how waste management dominates both FET and MET impacts, since all substances included in waste are assumed to be eventually released in the environment. If long term emissions were excluded from the assessment, both impacts would be lowered by one order of magnitude and the impacts of pesticides would be much more relevant (see section S4 of the supplementary material). Last, another source of uncertainty linked to the toxicity related categories has been found, associated to pesticide emission modelling (van Zelm et al., 2014). Again, an inconsistency is found between the fate models used in the two major sources of inventory data. In Ecoinvent $\mathrm{LCl}$ data it is assumed that the full quantity of pesticides applied are directly emitted to the soil. Thus, the fate process is left to be handled by the characterisation model. The USEIO database, however, splits agrochemical emissions among air, water and soil compartments. To do so, a simplified partitioning calculation based on vapour pressure (Suh, 2010) is used, and thus that of the characterisation model is not employed.

When focusing on MD impacts, the prevalence of iron extraction is caused again by the USEIO database, since iron is the only metal included there. Regarding fossil depletion, the lack of specificity of the USEIO database also limits the accuracy of the results, since it only includes a generic fossil consumption category with an average characterisation factor (energy, 
unspecified). The lack of specificity of the substance coverage in the USEIO hinders the applicability of both MD and FD NFs. An uncertainty score is assigned to all NFs in section 4.3.1.

Last, water depletion and agricultural land occupation NFs are not expected to have high uncertainties: in those processes occurring in Galicia, both land use and water consumption figures included in $\mathrm{LCl}$ inventories have been modified to reflect the actual Galician conditions. For the remaining ones, no incongruences have been found between the two $\mathrm{LCl}$ data sources, which are assumed to represent average values of both water consumption and land occupations.

\subsection{Comparison of the normalised results of Galician products}

This section compares the normalised impacts of the aforementioned case studies (section 3.2) with those obtained using alternative normalisation datasets. The comparison is meant to evaluate how the use of different references could affect the interpretation of the impacts in both comparative case studies, and how it could influence decision making.

Even though several other normalisation datasets exist for Europe and the world, it is only possible to compare our NFs to those calculated with the same LCIA method, Thus, the most recent European and Global NFs obtained using the methodology ReCiPe Midpoint (H) v1.13 available in SimaPro v8.3 have been chosen (PRé Consultants, 2016).

It should be noted that different system limits are considered in the three sets of normalisation factors: the Galician normalisation factors consider a life cycle perspective, and thus include all direct and indirect emissions linked to production or consumption activities. The ReCiPe European values, however, only include the direct emissions happening in Europe, thus neglecting that numerous raw materials are imported from elsewhere. Last, the Recipe Global NFs also consider direct emissions only but, given their worldwide coverage, direct and indirect emissions are accounted for in practice.

\section{Canned tuna production case study}

Figure 6 focuses on the canned tuna case study, and compares the normalised results obtained with the Galician production NFs to those obtained with ReCiPe normalisation datasets for Europe (ReCiPe EU) and the World (ReCiPe GLO). Impact categories have been reordered so that the Galician normalised results of the 2005 supply chain are ranked in descending order. To obtain these values, all normalisation references (Galicia, ReCiPe EU and ReCiPe GLO) have been expressed per euro of GDP (and all figures have been converted to 2017 Euros to guarantee consistency). GDP data for Europe and the World in 2000 have been taken from (The World Bank, 2017). 


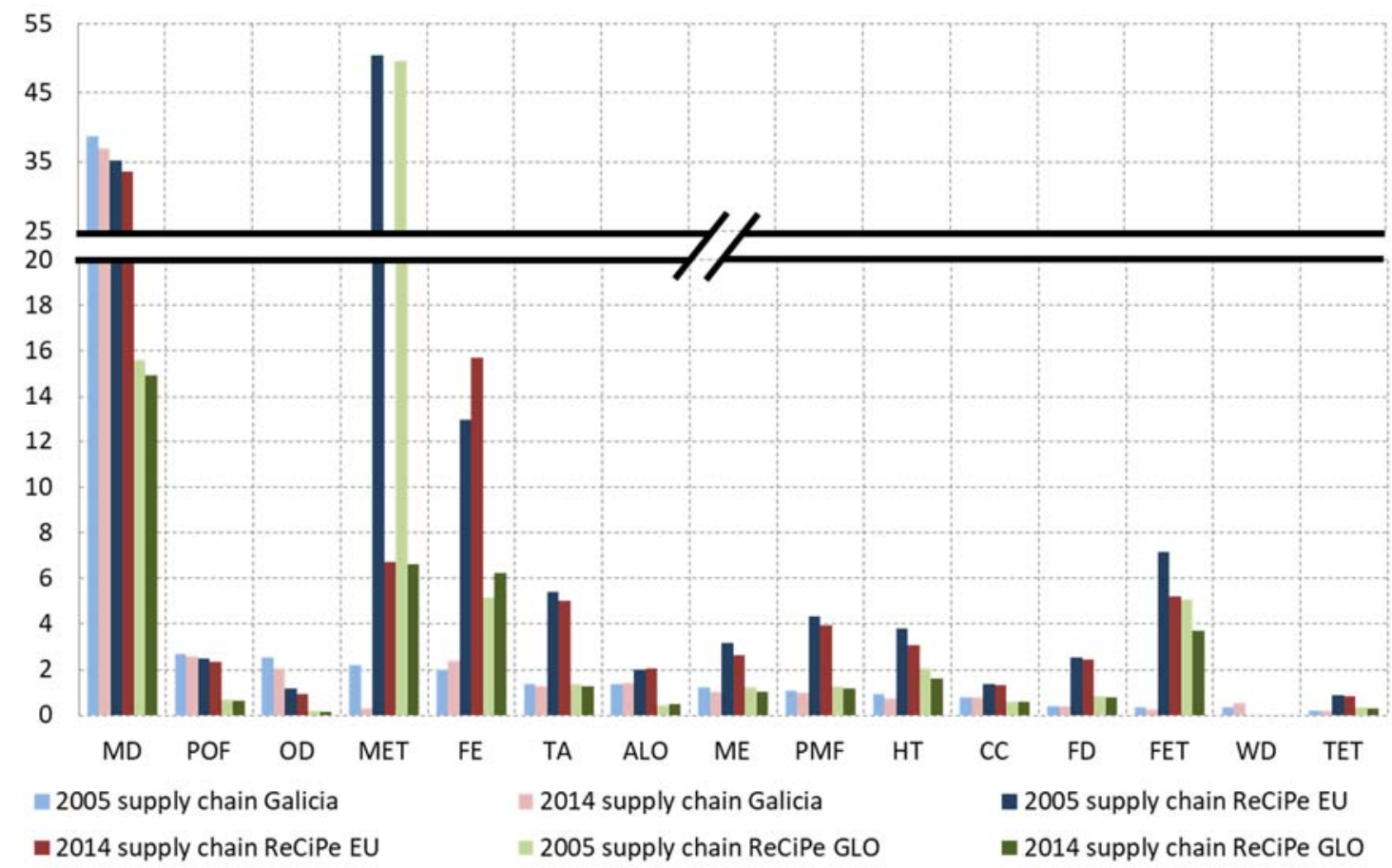

Figure 6: Normalised LCIA results (per euro) of the previous (2005) and current (2014) canned tuna supply chain, using three normalisation datasets: the Galician production NFs and the ReCiPe European and Global NFs. Fifteen impact categories have been considered: CC(climate change), OD (ozone depletion), TA (terrestrial acidification), FE (freshwater eutrophication), ME (marine eutrophication), HT (human toxicity), POF (photochemical oxidant formation), PMF (particulate matter formation), TET (terrestrial ecotoxicity), FET (freshwater ecotoxicity), MET (marine ecotoxicity), ALO (agricultural land occupation), WD (water depletion), MD (metal depletion) and FD (fossil depletion).

The impact category to which the current canned tuna supply chain contributes the most is MD in all three references systems (Figure 6). However, when the 2005 supply chain is analysed using ReCiPe NFs, the MET category acquires higher relevance, being MD ranked $2^{\text {nd }}$. This difference may influence decision making, since stakeholders could prioritise actions aimed at reducing the highest environmental impact. If all impact categories were ranked according to the contribution of the 2005 supply chain to the total per Euro impacts (as done in figure 6 for the Galician NFs), the rank position of OD, the $3^{\text {rd }}$ impact category when using Galician references, would fall to the $13^{\text {th }}$ or $14^{\text {th }}$ position, respectively, if European or World values were used. Similarly, the relevance of the POF category (ranked $2^{\text {nd }}$ here) would be much lower if ReCiPe values were used $\left(10^{\text {th }}\right)$. The opposite would happen to the FET category, ranked much higher $\left(4^{\text {th }}\right)$ in both Recipe references than in the Galician ones $\left(13^{\text {th }}\right)$. The remaining categories do not experience significant variations among reference systems. It should be noted that ReCiPe does not include WD normalisation factors, and thus a comparison is not possible for this impact category.

The characterisation results (Figure 2) showed that the current tuna supply chain had better environmental performance than the older one, except for FE, WD and ALO impact categories. When these results are normalised against different references (Figure 6), ALO experiences the most significant ranking variation: it ranks higher here (7th) than when using European (11th) or World (12th) references, but it is never a dominant impact category. FE, however, experiences a lower ranking variation, rising from 5th in Galicia to 3rd in Europe and the World, and becoming one of the highest impacts when ReCiPe is used. Thus, if the case study was evaluated using ReCiPe NFs only, the higher contribution to FE of the new supply chain would be highlighted. 


\section{Banana consumption case study}

Figure 7 focuses on the organic and conventional banana consumption case study.

In this case, impact categories have been reordered so that the Galician normalised results of conventional banana are ranked in descending order.

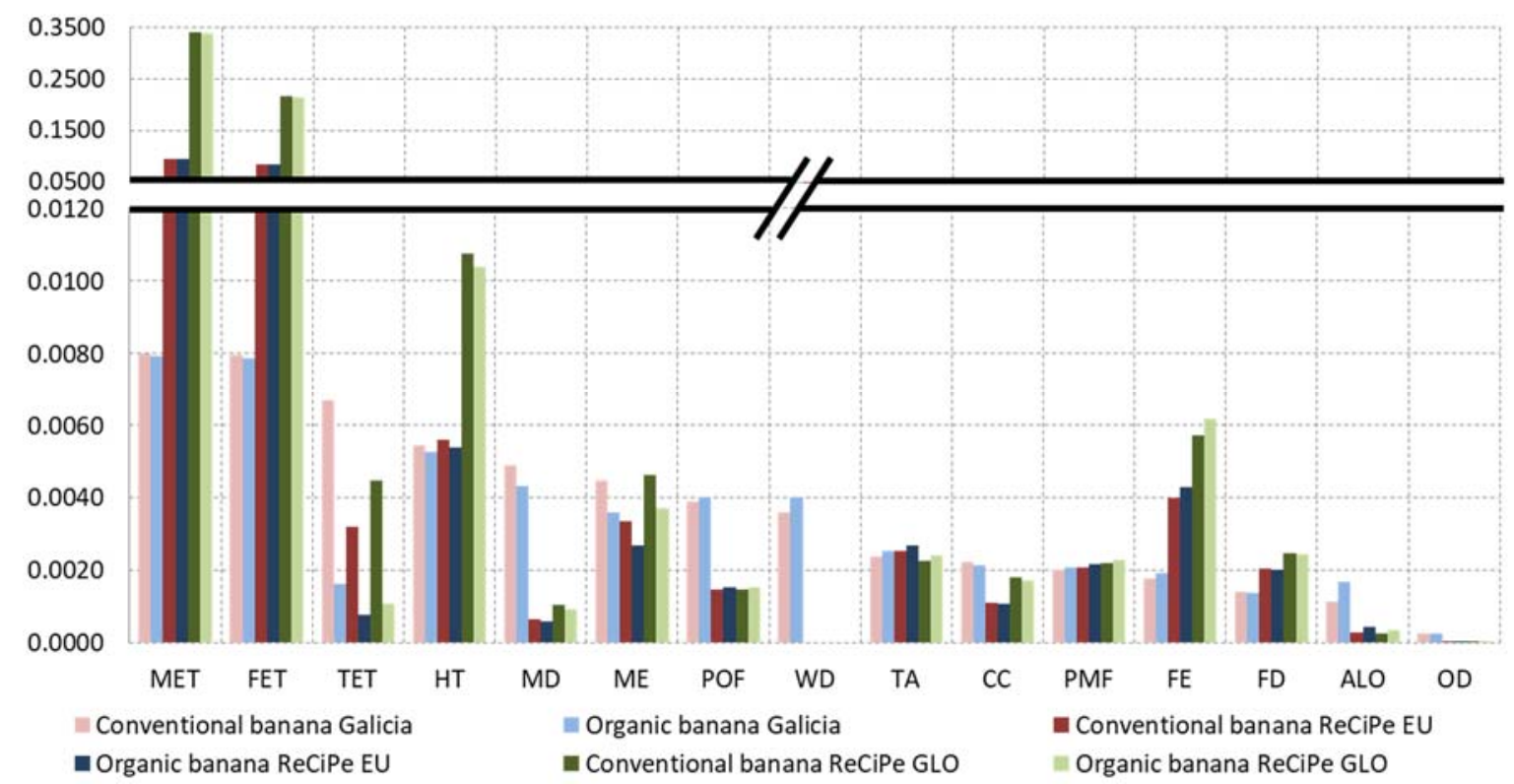

Figure 7: Normalised LCIA results of organic and conventional banana yearly consumption per capita, using three normalisation datasets: the Galician consumption NFs and the ReCiPe European and Global NFs. Fifteen impact categories have been considered: CC(climate change), OD (ozone depletion), TA

(terrestrial acidification), FE (freshwater eutrophication), ME (marine eutrophication), HT (human toxicity), POF (photochemical oxidant formation), PMF (particulate matter formation), TET (terrestrial ecotoxicity), FET (freshwater ecotoxicity), MET (marine ecotoxicity), ALO (agricultural land occupation), WD (water depletion), MD (metal depletion) and FD (fossil depletion).

Unlike the canned tuna case study, the dominant impact categories (MET and FET) are the same using all three normalisation references, but the relative contribution of banana consumption to the yearly impacts of an average citizen from the World or Europe is much higher than those of a Galician one. This implies that the annual Galician impacts per capita (NFs) in both categories are much higher than in Europe or the World. The impacts of HT are much higher when the World reference is used, while those obtained with Galician NFs are very similar to the European ones, meaning that the normalisation value (annual impacts per capita) calculated for Galicia and for Europe are similar, and much lower than that of the World.

If all impact categories were ranked according to the contribution of conventional banana to the total per capita impacts, the rank position of HT would not vary significantly, being ranked $4^{\text {th }}$ for Galicia and $3^{\text {rd }}$ for both ReCiPe references. On the contrary, FE and MD impacts would vary their relative position in a notable way: $M D$ would fall from the current $5^{\text {th }}$ position to the $12^{\text {th }}$ if any of the ReCiPe datasets were used, while FE would rise from the current $12^{\text {th }}$ position to the $4^{\text {th }}$ one. The remaining impact categories would not experience large position variations, and again WD results cannot be compared since ReCiPe values are not available.

Figure 4 showed that organic bananas had a better environmental performance than conventional ones in almost all impact categories, except for TA, FE, PMF, ALO, WD, and POF. Among them and as already mentioned, the only category which experiences a significant ranking variation is $\mathrm{FE}$, and so if the case study was evaluated using ReCiPe NFs, the slightly lower contribution of conventional bananas in this category would be highlighted. 
Broadly speaking, important differences are found among the ranking position of the impact categories between the Galician references and the ReCiPe ones, being the variations between both ReCiPe references (European or Global) much less important. The similarities between both ReCiPe datasets respond to the use of the same methodologies and data sources, since both the European and World inventories have been extrapolated from the data available in a few countries only (Sleeswijk et al., 2008). The choice of a particular region here with its own characteristics in terms of human activities, and the use of a life cycle perspective (and thus a different methodology), can explain the differences found between the Galician and ReCiPe reference systems.

On the one hand, the average European or World references chosen in ReCiPe probably do not reflect the particular consumption patterns and economic characteristics of a small economy such as the Galician one. As an example, energetic consumption in households is expected to be much lower in this southern region than in an average European country. This probably explains the lower Galician NFs for those impact categories to which energy consumption contributes the most (CC, POF, MD), when compared to the ReCiPe European ones. Regarding the production activities, the density of the bovine livestock sector (in heads per hectare) is $50 \%$ higher in Galicia than in the average European country (Eurostat, 2017a; IGE, 2015a). This probably explains the higher NFs of the categories to which the primary sector contributes the most (TET and ME). Last, the Galician urban waste management mix differs greatly from Galicia to the rest of Europe, and this activity is accounted for both in the Galician consumption and production NFs. Incineration is applied in Galicia to $42 \%$ of the urban waste, a much higher figure than that of Europe (6\%(Eurostat, 2017c)). Since waste incineration is the main contributor to FET and MET impact categories (both for consumption and production NFs), this probably explains the higher value of both Galician NFs when compared to ReCiPe ones.

On the other hand, ReCiPe NFs only consider the direct emissions happening in a certain territory. In our approach, we consider life cycle emissions occurring not only in Galicia but also elsewhere (direct and indirect emissions). This difference of approach mainly affects the Galician production NFs: if our approach were applied to all regions in the world, the total impacts would be higher than the actual worldwide emissions. The reason behind this is that some of the impacts would be accounted for twice: e.g. the impacts of the raw materials used in Galician industries but coming from a different region, would be accounted for in the NFs of both of them. Thus, the different approaches followed in both Galician and ReCiPe normalisation references also lead to changes in the normalised results when Galician production NFs are used. This difference does not affect consumption NFs, since starting from the final consumption of the inhabitants of a certain region avoids the aforementioned addition problems, even when territorial LCA is used.

Even though using different NFs did not alter the main conclusions drawn from both case studies, this evaluation shows how the choice of different normalisation datasets can affect decision making. The fact that the dominant impact categories of both case studies coincide among normalisation references (Galicia and ReCiPe) confirms that lowering those impacts is the right path to follow by decision makers to reduce the overall environmental impacts of the Galician region. However, important ranking differences appeared in some environmental categories (such as FE in bananas and OD in canned tuna). Thus, as advised by (ISO, 14044:2006), using different reference systems can help decision making both if they lead to the same conclusion (proving its robustness) or to different ones (indicating the need for further investigation, or to consider the uncertainties of both references). The NFs calculated here provide a different reference dataset to be used in Galician studies along with that of ReCiPe. 


\subsection{Appropriateness of territorial LCA for the calculation of normalisation factors}

This section is aimed at evaluating the suitability of using territorial LCA to calculate normalisation datasets. First, an analysis of the uncertainty of the normalisation factors obtained for Galician production and consumption is provided. Afterwards, a general evaluation of the methodology is proposed and further improvements for subsequent studies are presented.

\subsubsection{Uncertainty analysis}

An evaluation of the uncertainty of the normalisation datasets should always be made available (Pizzol et al., 2016). Even though quantitative evaluations would be desirable (Sala et al., 2015), the lack of data usually leads authors to qualitative evaluations (Huijbregts et al., 2003; Sleeswijk et al., 2008), in which impact categories are classified into groups based on their level of uncertainty. A qualitative analysis has also been performed here (Table 3).

Uncertainty in normalisation factors is originated by both uncertainty in emission data (inventories) and uncertainty in characterisation factors (Sleeswijk et al., 2008). The former refers mainly to the lack of substances included in the inventories, while the latter includes both the possible lack of characterisation factors and the uncertainty linked to fate, effect and exposure models used in impact determination. An uncertainty analysis has been designed here to account for both sources.

Moreover, a third source of uncertainty has been considered here due to the use of a hybrid methodology, combining different $\mathrm{LCl}$ data sources which may follow inconsistent approaches. Following (Sala et al., 2015), the uncertainty linked to the lack of substances in the inventory data used has been evaluated by comparing the inventoried substances to those included in the ReCiPe methodology (i.e. having characterisation factors). Each category obtains a score based on the level of coverage of its inventory: 3 (good), 2 (fair), and 1 (poor), which is shown in the first column of Table 3. A table detailing the number of flows covered and leading to those values is available in section $\mathrm{S} 5$ of the supplementary material.

Regarding the uncertainty of characterisation factors, each impact has also been given a score, based on the uncertainty of the modelling used in ReCiPe: the highest score (3) has been given to those methods having widely accepted characterisation factors (e.g. included in the ILCD recommendations (EC-JRC, 2011)), or whose characterisation factors do not reflect an impact pathway but more of an inventory analysis (ALO, WD). The lowest score (1) has been awarded to those impact categories usually linked to high uncertainties (i.e. toxicity related categories) (Sleeswijk et al., 2008). An intermediate score (2) has been given to the remaining impact categories. This classification is included in the second column of table 3 .

The last source of uncertainty originates from the use of two different $\mathrm{LCl}$ data sources (the USEIO database and Ecoinvent), since some differences in modelling approaches have been found between them (see section 4.1). The lowest score (1) is given to those impact categories in which these differences exist (inclusion/exclusion of long term emissions, different pesticide modelling). An intermediate value (2) is awarded when differences are found between the substances coverage in the two LCl sources (inclusion of outdated substances, use of generic compounds or exclusion of relevant elements in one of the $\mathrm{LCl}$ data sources). The highest score (3) is awarded to those impact categories where no discrepancies were found. These values are shown in column 3 of table 3.

All three uncertainty scores have been averaged, and a fourth column has been added where impact categories are classified into three levels of uncertainty: high (average score $<1.5$ ), medium ( $1.5<$ average score<2.5) or low (average score $>2.5$ ).

Table 3: Uncertainty evaluation of the impact categories included in both normalisation datasets. Three scores from 1 to 3 are given in three uncertainty sources, and their average value provides the global

level of uncertainty of each NF.

\begin{tabular}{|c|c|c|c|c|}
\hline \multirow[b]{2}{*}{ Impact category } & \multicolumn{3}{|c|}{ Uncertainty scores } & \multirow[b]{2}{*}{$\begin{array}{c}\text { Global level of } \\
\text { uncertainty }\end{array}$} \\
\hline & $\begin{array}{c}\text { Inventory } \\
\text { data }\end{array}$ & $\begin{array}{c}\text { Characterisation } \\
\text { factors }\end{array}$ & $\begin{array}{c}\text { Modelling } \\
\text { incongruences }\end{array}$ & \\
\hline
\end{tabular}




\begin{tabular}{|l|l|l|l|c|} 
CC & 2 & 3 & 3 & LOW \\
\hline OD & 3 & 3 & 2 & LOW \\
\hline TA & 3 & 2 & 3 & LOW \\
\hline FE & 2 & 3 & 1 & MEDIUM \\
\hline ME & 2 & 3 & 1 & MEDIUM \\
\hline HT & 2 & 1 & 1 & HIGH \\
\hline POF & 2 & 3 & 2 & MEDIUM \\
\hline PMF & 2 & 2 & 3 & MEDIUM \\
\hline TET & 1 & 1 & 2 & HIGH \\
\hline FET & 1 & 1 & 1 & HIGH \\
\hline MET & 1 & 1 & 1 & HIGH \\
\hline ALO & 3 & 3 & 3 & LOW \\
\hline WD & 3 & 3 & 3 & LOW \\
\hline MD & 1 & 2 & 2 & MEDIUM \\
\hline FD & & 2 & 2 & MEDIUM \\
\hline
\end{tabular}

As expected and often found in the literature, high levels of uncertainty are found for toxicity related categories (Laurent and Hauschild, 2015). The high uncertainty of the toxicity categories is a major issue in all normalisation datasets available (Lautier et al., 2010; Sala et al., 2015; Sleeswijk et al., 2008), and also for all LCIA results, and it is directly linked to the uncertainty of their characterisation factors. This issue also affects the Galician NFs and, like when other reference systems are used, it could hinder decision making. Thus, stakeholders basing their decisions on toxicity normalised impacts should be aware of the high uncertainty always linked to these categories, and know that the NFs may not accurately reflect the actual toxicity levels.

Eutrophication categories get intermediate levels of uncertainty (mainly due to the incongruences found in modelling), along with metal and fossil depletion, photochemical oxidant formation and particulate matter formation (due to inventory incompleteness or the use of generic categories). The remaining impact categories are considered to have low levels of uncertainty.

\subsubsection{General evaluation and prospective improvements}

This section emphasizes the usefulness of the Galician normalisation factors, summarizes the main advantages and disadvantages of using territorial LCA to calculate subnational NFs, and proposes improvement measures to overcome the drawbacks in subsequent studies.

The normalisation factors for Galician production and consumption reflect the total yearly environmental impacts of all regional activities. Then, normalised results express the environmental impacts relative to the total impacts in this area. The production NFs could be used to normalise the LCIA results of products manufactured in Galicia. Likewise, the consumption NFs could be used when the LCIA study refers to a product which is consumed in Galicia (no matter where its manufacturing takes place).

In both cases, the normalised results help decision makers to identify which product impacts should be reduced in regards to the overall impacts of the region: those that contribute the most to the environmental issues of the area (i.e. those impacts having the highest normalised values). This is important for local stakeholders in charge of developing projects, plans or programs that have low impacts on the environment. With subnational NFs, they know the contributions of their activities to the overall impacts of their region, and this can help to determine where the main improvements can be done to decrease these impacts.

Moreover, the territorial LCA methodology used allows calculating the total impacts of the region, used here as normalisation factors, but which also represent an environmental baseline of the area, disaggregated into its contributing activities (see S2). Thus, these disaggregated impacts could be useful for policy making, by acting on those activities having the higher impacts both for production and consumption: 
When focusing on the consumption based NFs, the main contributing activities to most impacts are food consumption and household consumption. Within the former, the consumption of animal based products stands out, being the most polluting activity in 5 out of 7 impact categories. Thus, policy recommendations on this subject could focus on reducing the consumption of livestock-based foodstuff. This suggestions would be in line with that of the Galician Health Service, which recently published a decalogue of tips to improve nutrition (SERGAS, 2016), in which the lowering of the consumption of meat and dairy derivatives was recommended. Concerning to household consumption, electricity and heating are the activities that contribute the most to 4 out of 6 impacts. Thus, policy recommendations should encourage the use of clean energies. An example of this kind of policy is the subsidy provided by the Galician government to install photovoltaic panels in residential buildings (INEGA, 2017). Moreover, the Galician electricity mix should be improved by switching to renewable sources of energy, since in 2014 31\% of the Galician electricity came from coal burning (REE, 2014). Initiatives such as the Galician regulation authorising new wind farms in the region (Xunta de Galicia, 2010) could help lowering these impacts.

When focusing on the production based NFs, the main contributing activities to the impacts are electricity production (major contributor to 4 impact categories), food production (3 categories), and agricultural and livestock products ( 2 categories). The same policies recommended for consumption could also be used for reducing production impacts: switching to a more renewable energetic mix would lower impacts related to coal burning. Moreover, more attention should be paid to the agricultural and livestock sector, where the use of pesticides and fertilisers should be optimized, and the emissions linked to enteric fermentation and manure management should be reduced. Seeking to lower the environmental impacts of the agroforestry sector, the Galician government recently published good practice guidelines (Xunta de Galicia, 2014a), to help designing the optimal dosages of pesticides and fertilisers for different crops. Moreover, the most recent Rural Development Plan approved in Galicia (Xunta de Galicia, 2014b) foresees financial support for improvements in manure and slurry management facilities, leading to lower environmental impacts.

The life cycle perspective considered for both production and consumption activities when determining the Galician normalisation factors is probably the main advantage of both datasets. This perspective guarantees that the system boundaries of the normalisation factors are compatible with those of most product LCAs. Normalisation factors referred to consumption are often scarce. To the best of our knowledge, they only exist so far for The Netherlands, Finland and Canada; while production normalisation factors do not consider a life cycle perspective: they only include the total emissions of a certain region (e.g. Europe), neglecting that numerous raw materials are imported from elsewhere. Normalisation datasets for Galician consumption and production have been obtained here, thus adding new datasets to those currently available and proposing the use of a new methodology to obtain normalisation values in different regions.

Moreover, both production and consumption datasets are also made available per consumption/production activity (see section S2 of the supplementary material), always following this life cycle perspective, so that each product consumed or produced in Galicia that needs to be evaluated can be compared to the total impacts linked to that type of products.

Last but not least, both normalisation datasets have been calculated for Galicia, a region in which numerous LCA studies are carried out and for which no normalisation factors existed so far. The new normalisation datasets can be used in sensitivity analysis, since it is recommended to use several reference systems when using normalisation for decision making (Dahlbo et al., 2013). Numerous authors have pointed at the relevance of this regionalisation, which is often consistent with policy targets (Breedveld et al., 1999) and makes normalised results more intuitive to decision makers (Lautier et al., 2010). The major drawback of regionalization (the exclusion of the impacts occurring outside the territory under study) is overcome here by means of the life cycle perspective. 
Using territorial LCA to calculate normalisation factors has however, some disadvantages. A 2002 US database has been used to characterise numerous inventories: this database was chosen due to the large list of environmental flows included, to the extensive list of activities covered, and to an easy correspondence of those activities to the Galician production and consumption inventory data. However, it is a quite old database that reflects the United States conditions, which are not necessarily similar to the Galician ones.

Another drawback is linked to data gaps: some activity descriptors were not available for 2014 or for Galicia, and thus older data had to be used and extrapolations from Spanish data were required at some points. Regarding inventory data, it is incomplete for the services sector, since it only includes its emissions linked to energy use, water consumption and wastewater generation, thus probably underestimating the life cycle emissions of the activities belonging to that sector.

Moreover, using territorial LCA implies large data requirements, which may not be available for all regions, and thus the calculation of normalisation factors is very time consuming, which can also hinder its implementation in other regions.

Last, some incompatibilities were detected between Ecoinvent and USEIO modelling, such as the treatment of long term emissions. Moreover, a procedure had to be used to avoid double counting, which may increase the uncertainty of the results.

A few prospective improvements can be recommended to the methodology, based on the aforementioned disadvantages. First, the use of a Multi-Region Input Output (MRIO) database could improve the reliability of the results, considering not only more accurate emissions for Galician goods but also for those imported. Ideally, the new 10 database should also be disaggregated enough to guarantee the accuracy of the results, since aggregated 10 models are linked to great uncertainties (Yang et al., 2017). (Exiobase (2014)) seems to be a promising alternative, being a MRIO database containing European data. However, its use has been discarded so far due to the following limitations: i) the current format of the database, which is only available in Excel format and, due to the large amounts of data included, requires using specific software and implies long computation times, and ii) the lack of correspondences among the inventories included there and the data descriptors used here, corresponding to NACE categories. If the database were implemented in LCA software, its usability would be very much increased and correspondences among the inventories available and the data descriptors used in territorial LCA could be studied.

Having up-to-date, same year data for all the activities would improve the accuracy of the results, and facilitate its replication in the same region. More complete inventory data for the services sector should also be made available.

\section{Conclusions}

The feasibility of using territorial LCA to determine normalisation factors of the production and consumption activities of a certain region has been evaluated. The methodology has been proven useful to determine normalisation datasets following a life cycle perspective, and thus considering system boundaries that are compatible with most product LCAs.

Some weaknesses in the methodology have been identified, and improvement proposals to overcome them have been proposed. The most important one would be the use of a more recent, MRIO database instead of the 2002 US one: a few modelling discrepancies have been found between the USEIO database and the Ecoinvent database, that may affect the accuracy of the results and that could be solved by using a different 10 model. Moreover, the use of more detailed inventories for the services sector and of more recent activity descriptors, when available, could also improve the representativeness of the normalisation datasets.

Normalisation factors for Galician production and consumption have been calculated, and their interest and usability have been discussed by means of two case studies. The comparison of the normalised results of those case studies when using different reference systems has 
highlighted the need to compare several datasets when applying normalisation, to ensure the robustness of the conclusions when case studies are evaluated. Thus, the present study represents a relevant contribution to the body of knowledge on normalisation, proposing a new framework for NF determination and providing two new normalisation datasets.

\section{Acknowledgements}

This research did not receive any specific grant from funding agencies in the public, commercial, or not-for-profit sectors. This work was started during a research stay of L. Roibás at the ELSA Research Group for Environmental Lifecycle and Sustainability Assessment. L. Roibás and A. Hospido belong to Galician Competitive Research Group GRC 2013-032 and to the CRETUS Strategic Partnership (AGRUP2015/02). All these programmes are co-funded by FEDER (UE).

\section{References}

$A B C, 2015$. Citroën aspira a que el $70 \%$ de sus ventas en España sean de producción nacional. http://www.abc.es/local-galicia/20150514/abci-citroen-produccion-vigo-201505131957.html. Acessed: 15/12/2017.

Bare, J., Gloria, T., Norris, G., 2006. Development of the method and US normalization database for life cycle impact assessment and sustainability metrics. Environmental Science \& Technology 40, 5108-5115.

Breedveld, L., Lafleur, M., Blonk, H., 1999. A framework for actualising normalisation data in LCA: Experiences in the Netherlands. The International Journal of Life Cycle Assessment 4, 213220.

Dahlbo, H., Koskela, S., Pihkola, H., Nors, M., Federley, M., Seppälä, J., 2013. Comparison of different normalised LCIA results and their feasibility in communication. The International Journal of Life Cycle Assessment 18, 850-860.

Doka, G., 2009. Life Cycle Inventory of the disposal of lignite spoil, coal spoil and coal tailings. St. Gallen, Switzerland: Doka Life Cycle 18.

EC-JRC, 2011. Recommendations based on existing environmental impact assessment models and factors for life cycle assessment in the European context. https://www.google.es/url?sa=t\&rct=j\&q=\&esrc=s\&source=web\&cd=1\&cad=rja\&uact=8\&ved= OahUKEwjd3 LZqqnVAhWEfRoKHYKBCLUQFggsMAA\&url=http\%3A\%2F\%2Feplca.jrc.ec.europa. eu\%2Fuploads\%2FILCD-Recommendation-of-methods-for-LCIAdef.pdf\&usg=AFQjCNHEyAAIVSYHeDK7wQGrc83QFOw2jA. Acessed: 27/07/2017.

ECHA, 2017. European Chemicals Agency. Chemicals subject to PIC. https://echa.europa.eu/information-on-chemicals/pic/chemicals. Acessed: 20/09/2017.

EPA, 2017. Methyl Bromide. https://www.epa.gov/ods-phaseout/methyl-bromide. Acessed: 20/07/2017.

Eurostat, 2008. NACE Rev. 2-statistical classification of economic activities in the European Community. http://ec.europa.eu/eurostat/documents/3859598/5902521/KS-RA-07-015EN.PDF. Acessed: 25.04.2016.

Eurostat, 2017a. Bovine population - annual data. http://ec.europa.eu/eurostat/statisticsexplained/index.php/Agricultural production - animals. Acessed: 17/12/2017.

Eurostat, 2017b. Supply, transformation and consumption of electricity - annual data. http://ec.europa.eu/eurostat/statistics-

explained/index.php/Electricity production, consumption and market overview. Acessed: $17 / 12 / 2017$.

Eurostat, 2017c. Treatment of waste by waste category, hazardousness and waste operations [env_wastrt]. 
http://appsso.eurostat.ec.europa.eu/nui/show.do?dataset=env wastrt\&lang=en. Acessed: 17/12/2017.

Exiobase, 2014. Exiobase data download. http://www.exiobase.eu/index.php/datadownload/exiobase2-year-2007-full-data-set. Acessed: 07/06/2016.

Faro de Vigo, 2015. Vigo y la provincia lideran el crecimiento de las ventas de coches en la comunidad. http://www.farodevigo.es/economia/2015/01/03/vigo-provincia-liderancrecimiento-ventas/1159143.html. Acessed: 15/12/2017.

Goedkoop, M., Heijungs, R., Huijbregts, M., De Schryver, A., Struijs, J., van Zelm, R., 2009. ReCiPe 2008. A life cycle impact assessment method which comprises harmonised category indicators at the midpoint and the endpoint level 1.

Hellweg, S., Frischknecht, R., 2004. Evaluation of long-term impacts in LCA. The International Journal of Life Cycle Assessment 9, 339-341.

Hospido, A., Vazquez, M.E., Cuevas, A., Feijoo, G., Moreira, M.T., 2006. Environmental assessment of canned tuna manufacture with a life-cycle perspective. Resources, Conservation and Recycling 47, 56-72.

Huijbregts, M., Breedveld, L., Huppes, G., De Koning, A., Van Oers, L., Suh, S., 2003. Normalisation figures for environmental life-cycle assessment: The Netherlands (1997/1998), Western Europe (1995) and the world (1990 and 1995). Journal of Cleaner Production 11, 737748.

Huijbregts, M.A., Steinmann, Z.J., Elshout, P.M., Stam, G., Verones, F., Vieira, M., Zijp, M., Hollander, A., van Zelm, R., 2017. ReCiPe2016: a harmonised life cycle impact assessment method at midpoint and endpoint level. The International Journal of Life Cycle Assessment 22, 138-147.

IGE, 2015a. Número de bovinos por clase. Galicia e provincias. Ano 2014. https://www.ige.eu/igebdt/esqv.jsp? paxina $=001 \& c=0301005 \&$ ruta $=v e r P p a l e s R e s u l t a d o s . j s p ?$ $O P=1 \& B=1 \& M=\& C O D=2917 \& R=1[1: 2: 4: 5: 3] \& C=9912[a l l] \& F=T[1: 0] ; 2: 1 ; 3: 11 \& S=\& T I=3$.

Acessed: 17/12/2017.

IGE, 2015b. Poboación ocupada por sexo, grupos de idade e sector económico (CNAE 2009). Galicia. Metodoloxía EPA 2005. http://www.ige.eu/igebdt/esqv.jsp?ruta=verTabla.jsp?OP=1\&B=1\&M=\&COD=6358\&R=1[0];2[ 0];0[2014]\&C=3[0]\&F=\&S=\&SCF=. Acessed: 27/09/2017.

IGE, 2015c. Poboación segundo sexo e idade. http://www.ige.eu/igebdt/esqv.jsp?ruta=verTabla.jsp?OP=1\&B=1\&M=\&COD=590\&R=9912[12] 2[2013:2014:2015];0[0]\&C=1[0]\&F=\&S=\&SCF=. Acessed: 05.04.2016.

INE, 2014a. Cantidad total y cantidades medias consumidas de alimentos, bebidas, tabaco, combustibles y otras fuentes de energía. http://www.ine.es/jaxiT3/Datos.htm?t=10698. Acessed: 27/09/2017.

INE, 2014b. Gasto total y gastos medios de los hogares. http://www.ine.es/jaxiT3/Datos.htm?t=10724. Acessed: 03.03.2016.

INE, 2016a. Cálculo de variaciones del Indice de Precios de Consumo (sistema IPC base 2011). http://www.ine.es/varipc/. Acessed: 05.04.2016.

INE, 2016b. Contabilidad Regional de España. Base 2010. Serie contable. http://www.ine.es/jaxi/Tabla.htm?path=/t35/p010/base2010/l0/\&file=01001.px\&L=0.

Acessed: 09/06/2017.

INEGA, 2017. SUBVENCIÓNS PARA O ANO 2017 PARA PROXECTOS DE INSTALACIÓNS DE FOTOVOLTAICA NAS COMUNIDADES DE PROPIETARIOS. http://www.inega.gal/subvencions/subvencions/Energiasrenovables/2017/ficha renovables20 17 0006.html. Acessed: 02/01/2018.

IPCC, 2013. Summary for Policymakers, Climate Change 2013: The Physical Science Basis. Contribution of Working Group I to the Fifth Assessment Report of the Intergovernmental Panel on Climate Change. [Stocker,T.F., D. Qin, G.-K. Plattner, M. Tignor, S.K. Allen, J. 
Boschung, A. Nauels, Y. Xia, V. Bex and P.M. Midgley (eds.)]. Cambridge University Press, Cambridge, United Kingdom and New York, NY, USA.

ISO, 14040:2006. ISO/TS 14040:2006. Environmental Management - Life Cycle Assessment Principles and Framework. International Standards Organisation, Geneva.

ISO, 14044:2006. ISO/TS 14044:2006. Environmental Management - Life Cycle Assessment Requirements and Guidelines. International Standards Organisation, Geneva.

Kaenzig, J., Jolliet, O., 2006. Consommation respectueuse de l'environnement: décisions et acteurs clés, modèles de consommation. Report, Office fédéral de l'environnement (OFEV), Berne.

Kim, J., Yang, Y., Bae, J., Suh, S., 2013. The importance of normalization references in interpreting life cycle assessment results. Journal of Industrial Ecology 17, 385-395.

Laurent, A., Hauschild, M.Z., 2015. Normalisation, in: Hauschild, M.Z., Huijbregts, M.A.J. (Eds.), Life Cycle Impact Assessment. Springer Netherlands, Dordrecht, pp. 271-300.

Lautier, A., 2010. METTRE EN CONTEXTE LES RÉSULTATS D'UNE ANALYSE DE CYCLE DE VIE: DÉVELOPPEMENT DE FACTEURS DE NORMALISATION CANADIENS ET PROBLÉMATIQUE DE LA DÉFINITION DES FRONTIÈRES ÉCOLE POLYTECHNIQUE DE MONTRÉAL

Lautier, A., Rosenbaum, R.K., Margni, M., Bare, J., Roy, P.-O., Deschênes, L., 2010. Development of normalization factors for Canada and the United States and comparison with European factors. Science of the Total Environment 409, 33-42.

Loiseau, E., Roux, P., Junqua, G., Maurel, P., Bellon-Maurel, V., 2013. Adapting the LCA framework to environmental assessment in land planning. The International Journal of Life Cycle Assessment 18, 1533-1548.

MAGRAMA, 2014. Anuario de 2013. http://www.magrama.gob.es/es/estadistica/temas/publicaciones/anuario-deestadistica/2013/default.aspx. Acessed: 10.10.2015.

MAPAMA, 2015. Informe del Consumo Alimentario en España 2014. http://www.mapama.gob.es/es/alimentacion/temas/consumo-y-comercializacion-y-

distribucion-alimentaria/informeconsumoalimentacion2014 tcm7-382148.pdf. Acessed: 15/12/2017.

Norris, G.A., 2001. The requirement for congruence in normalization. The International Journal of Life Cycle Assessment 6, 85-88.

Pizzol, M., Laurent, A., Sala, S., Weidema, B., Verones, F., Koffler, C., 2016. Normalisation and weighting in life cycle assessment: quo vadis? The International Journal of Life Cycle Assessment 6, 853-866.

PRé Consultants, 2016. SimaPro v8.3. https://simapro.com/. Acessed: 02/01/2018.

REE, 2014. El sistema eléctrico español. http://www.ree.es/es/publicaciones/sistema-electricoespanol/informe-anual/informe-del-sistema-electrico-espanol-2014. Acessed: 07.03.2016.

Roibás, L., Elbehri, A., Hospido, A., 2015a. Evaluating the sustainability of Ecuadorian bananas: Carbon footprint, water usage and wealth distribution along the supply chain. Sustainable Production and Consumption 2, 3-16.

Roibás, L., Elbehri, A., Hospido, A., 2016. Carbon footprint along the Ecuadorian banana supply chain: methodological improvements and calculation tool. Journal of Cleaner Production 112, Part 4, 2441-2451.

Roibás, L., García, D., Cuevas, A., Román, A., Hospido, A., 2015b. The environmental consecuences of changing a business strategy: Assessing the impact of offshoring on the carbon footprint of a seafood product, VI Conferencia Internacional de Análisis de Ciclo de Vida en Latinoamérica (CILCA), Lima, Perú.

Roibás, L., Loiseau, E., Hospido, A., 2017. Determination of the carbon footprint of all Galician production and consumption activities: Lessons learnt and guidelines for policymakers. Journal of Environmental Management 198, Part 1, 289-299. 
Sala, S., Benini, L., Mancini, L., Pant, R., 2015. Integrated assessment of environmental impact of Europe in 2010: data sources and extrapolation strategies for calculating normalisation factors. The International Journal of Life Cycle Assessment 20, 1568.

SERGAS, 2016. Alimentación y nutrición. http://www.sergas.es/Saude-publica/Alimentacionnutricion?idioma=es. Acessed: 20.10.2016.

Slapnik, M., 2015. Extending life cycle assessment normalization factors and use of machine learning - A Slovenian case study. Ecological indicators v. 50, pp. 161-172-2015 v.2050.

Sleeswijk, A.W., van Oers, L.F., Guinée, J.B., Struijs, J., Huijbregts, M.A., 2008. Normalisation in product life cycle assessment: An LCA of the global and European economic systems in the year 2000. Science of the Total Environment 390, 227-240.

Stranddorf, H.K., Hoffmann, L., Schmidt, A., 2005. Impact categories, normalization and weighting in LCA. Danish Ministry of the Environment. Environmental protection agency. Environmental news 78.

Suh, S., 2010. CEDA 4.0 User's Guide. https://www.presustainability.com/download/manuals/CEDAUsersGuide.pdf. Acessed: 03.03.2016.

The World Bank, $2017 . \quad$ GDP (current US\$).
https://data.worldbank.org/indicator/NY.GDP.MKTP.CD. Acessed: 06/11/2017.

van Zelm, R., Larrey-Lassalle, P., Roux, P., 2014. Bridging the gap between life cycle inventory and impact assessment for toxicological assessments of pesticides used in crop production. Chemosphere 100, 175-181.

Verones, F., Bare, J., Bulle, C., Frischknecht, R., Hauschild, M., Hellweg, S., Henderson, A., Jolliet, O., Laurent, A., Liao, X., Lindner, J.P., Maia de Souza, D., Michelsen, O., Patouillard, L., Pfister, S., Posthuma, L., Prado, V., Ridoutt, B., Rosenbaum, R.K., Sala, S., Ugaya, C., Vieira, M., Fantke, P., 2017. LCIA framework and cross-cutting issues guidance within the UNEP-SETAC Life Cycle Initiative. Journal of Cleaner Production 161, 957-967.

Wernet, G., Bauer, C., Steubing, B., Reinhard, J., Moreno-Ruiz, E., Weidema, B., 2016. The ecoinvent database version 3 (part I): overview and methodology. The International Journal of Life Cycle Assessment 21(9), 1218-1230.

Xunta de Galicia, 2010. ORDEN de 29 de marzo de 2010 para la asignación de 2.325 MW de potencia en la modalidad de nuevos parques eólicos en Galicia. https://www.xunta.gal/dog/Publicados/2010/20100331/AnuncioD1F2 es.html. Acessed: 02/01/2018.

Xunta de Galicia, 2014a. Guía de Buenas Prácticas. Agrícolas, Ganaderas y Forestales https://margalulla.xunta.es/sites/default/files/original/documentos/recurso/Guia\%20ES\%20Fi nal.pdf. Acessed: 02/01/2018.

Xunta de Galicia, 2014b. Programa de desarrollo rural 2014-2020. . http://mediorural.xunta.gal/fileadmin/arquivos/desenvolvemento/PDR/20142020/documento s programacion/PDR 20142020 v 2.2.pdf. Acessed: 02/01/2018.

Yang, Y., Heijungs, R., Brandão, M., 2017. Hybrid life cycle assessment (LCA) does not necessarily yield more accurate results than process-based LCA. Journal of Cleaner Production $150,237-242$. 